\title{
Sven Jochem
}

\section{Skandinavien}

\section{Einleitung}

Die politischen Systeme der nordeuropäischen Territorialstaaten sind bunter und vielschichtiger, als es vorhandene Vorstellungen von einem uniformen nordischen Modell der Demokratie nahelegen. Wenn daher im Folgenden vom (europäischen) Norden oder den skandinavischen Ländern die Rede ist, dann sind dies mitunter unpräzise Generalisierungen, die der Kürze der hier gebotenen Darstellung geschuldet sind (vgl. differenzierend Alestalo/Hort/ Kuhnle 2009, Bengtsson et al. 2013, Bergmann/ Strøm 2011, Henningsen/Jochem 2014, Jochem 2012).

Jenseits notwendiger Differenzierungen im Detail rangieren die nordischen Demokratien bei unterschiedlichsten empirischen Messverfahren der empirischen Demokratieforschung stets in der Gruppe der weltweit führenden Demokratien. ${ }^{1}$ Die Qualität nordischer Demokratien, die Qualität nordischen Regierens wird im internationalen Vergleich als besonderes Leistungsmerkmal des Nordens hervorgehoben. Die sehr gut ausgeprägte demokratische Transparenz und Zurechenbarkeit werde im Norden kombiniert mit einem ausgeprägten politischen Pragmatismus jenseits parteiprogrammatischer Grabenkämpfe sowie einer in Geschichte und Kultur des Nordens tief verankerten Vorstellung umfassend ausgeprägter individueller Autonomie und individueller Emanzipation auf gesellschaftlicher Ebene (vgl. hierzu beispielhaft Henningsen 2013, Holmberg/Rothstein 2012).

Die politischen Systeme des Nordens können in genuin parlamentarische Systeme (Dänemark, Norwegen, Schweden) und in semi-präsidentielle Systeme (Island, Finnland) unterteilt werden. In diesem Beitrag wird jedoch gezeigt, wie die semipräsidentiellen Systeme in den vergangenen zwei Dekaden zusehends Prinzipien des Parlamentarismus adaptierten. Dieser Trend wurde mit einer Verfassungsreform in Finnland (2000) verfassungsrechtlich festgeschrieben; in Island kann die geplante Verfassungsänderung allerdings mit der Wahl zum Parlament im April 2013 als gescheitert angesehen werden (Jochem 2013c).

Die meisten nordischen Staaten demokratisierten sich bereits relativ früh; dieser Prozess setzte sich bis in die Gegenwart ohne größere Rückschläge oder nationale Katastrophen fort. Einzig in Finnland stand die Demokratisierung in der Zwischenkriegszeit auf der Kippe. Aufbauend auf die Studien von Stein Rokkan (1999) und der

1 Als zwei von vielen Beispielen sei verwiesen auf: Freedomhouse (http://www.freedomhouse.org), Democracybarometer (http://www.democracybarometer.org). Vgl. auch Tabelle 11 in Kapitel 3 dieses Beitrags. 
dort verwendeten Metapher der vier Stufen einer Demokratisierung (Pressefreiheit, universelles Wahlrecht, proportionales Wahlrecht, parlamentarische Verantwortung) können die jeweiligen historischen Wegmarken in Skandinavien aus den Daten in Tabelle 1 abgelesen werden. Hieraus wird ersichtlich, dass vor allem in Finnland die demokratische Entwicklung spät startete und spät vollendet wurde.

Tab. 1: Demokratislerung und Staatsbildung in Skandinavien

\begin{tabular}{lllll}
\hline & $\begin{array}{l}\text { Legitimitat: } \\
\text { Pressefrelheit }\end{array}$ & $\begin{array}{l}\text { Einbindung: } \\
\text { Universelles } \\
\text { Wahlrecht }\end{array}$ & $\begin{array}{l}\text { Reprlsentatlon: } \\
\text { Proportionales } \\
\text { Wahlrecht }\end{array}$ & $\begin{array}{l}\text { Exekutive Macht: } \\
\text { Parlamentarismus }\end{array}$ \\
\hline Dannemark & 1849 & 1915 & 1915 & 1901 \\
Finnland & 1917 & 1906 & 1906 & 1917 \\
Island & 1849 & 1915 & $1959(1942)^{1)}$ & 1904 \\
Norwegen & 1814 & 1913 & 1919 & 1884 \\
Schweden & $1809(1766)$ & 1921 & 1909 & 1917 \\
\hline
\end{tabular}

Anmerkung: Die Jahreszahlen können je nach Quelleninterpretation schwanken. " Einige der Sitze im Althingi waren bereits seit 1942 dem proportionalen Wahlrecht unterworfen. Auf das gesamte Parlament wurde dies jedoch erst 1959 angewendet.

Quelle: Heidar 2004, S. 18

Die politischen Prinzipien der Gleichheit, des gesellschaftlichen Vertrauens, eines ausgeprägten politischen Pragmatismus sowie einer durch wenige institutionelle Politikverflechtungen gebremsten Mehrheitsherrschaft sind für die nordischen Länder charakteristisch. Im Norden - mit der Ausnahme Islands - wird eine durchschlagskräftige institutionelle Mehrheitsdemokratie kombiniert mit informellen Routinen der Konsenssuche und eines offenen Verhandelns und Debattierens in den hierfür vorgesehenen demokratischen Gremien als auch auf zivilgesellschaftlicher Ebene. Die spezifisch nordische Kombination aus lutherischer Reformation mit früher nationaler Staatsgründung sowie einer ebenso frühen staatlichen Modernisierung ist für diese Form der nordischen Verhandlungsdemokratie ebenso prägend gewesen wie die Einbettung staatlicher Institutionen in liberale und karitative Volksbewegungen (vgl. für Schweden: Jochem 2013b).

\section{Typen nordischer Regierungssysteme}

Als Gemeinsamkeiten der politischen Systeme des Nordens kann festgehalten werden, dass alle Territorialstaaten zentralistisch organisiert sind, sie hierbei aber auch über eine große Autonomie der regionalen bzw. lokalen Gebietskörperschaften verfügen. Ebenso ist den nordischen Demokratien gemein, dass sie in der klassischen Gewaltenteilungslehre über starke Parlamente und Exekutiven verfügen und die Judikative im politischen Prozess mit einem eher schwächeren Vetopotenzial ausgestattet ist. Die 
detaillierte Analyse dieser Aspekte wird im Folgenden durchgeführt. Zuvor sollen jedoch die drei autonomen Regionen des Nordens vorgestellt werden. ${ }^{2}$

Grönland ist Teil des dänischen Königreichs. Seit 1979 wurde Grönland eine weitreichende innenpolitische Autonomie eingeräumt. Am 25. November 2008 stimmte die Mehrheit der grönländischen Bevölkerung (mit über 75 Prozent der gültigen Stimmen) für eine weitgehende Unabhängigkeit Grönlands von Dänemark; die neuen Regelungen traten am 21. Juni 2009 in Kraft. Grönland besitzt ein eigenes Parlament (,Inatsisartut“) sowie eigenständige politische Akteure. Einzig im Bereich der Außenpolitik erfolgt noch eine Vertretung durch die dänische Regierung. Auch aus diesem Grunde entsenden die Grönländer zwei Abgeordnete ins dänische Parlament. Als Besonderheit ist der 1985 vollzogene Austritt Grönlands aus der EU zu interpretieren, seither hat Grönland den Status eines „assoziierten überseeischen Landes“ mit den Vorteilen der Zollunion sowie spezifischen Beziehungen insbesondere in den Bereichen Bildung und Umweltschutz.

Die Färöer Inseln sind völkerrechtlich ebenfalls ein Teil des dänischen Königreichs. Ähnlich wie Grönland besitzt die kleine Inselgruppe im Nordatlantik seit 1948 eine große innenpolitische Autonomie, wohingegen die Außen- und Sicherheitspolitik von der dänischen Regierung ausgeführt wird. Ebenso wie Grönland entsenden die Färöer Inseln daher zwei Abgeordnete in das dänische Parlament. Während die grönländische Bevölkerung für einen Austritt aus der EU stimmte, weigerte sich die Bevölkerung der Färöer Inseln in einem Referendum 1972 überhaupt erst, der EU beizutreten. Anders als Grönland mit seinem speziellen Status regelt die Regierung der Färöer die Beziehungen zur EU über bilaterale Verträge.

Åland schließlich stellt das dritte autonome Gebiet in Skandinavien dar. Historisch und sprachlich bestehen engste Verbindungen zu Schweden, allerdings war die Inselgruppe stets Teil der finnischen Republik. Bereits im Jahre 1856 wurde die Inselgruppe entmilitarisiert. Als im Jahr 1921 die Bewohner Ålands eine Aufnahme in das schwedische Königreich forderten, entschied sich der Völkerbund für einen staatsrechtlichen Status quo, räumte den Bewohnern der Inseln jedoch eine weitreichende innenpolitische Autonomie ein. Der Präsident der finnischen Republik hat ein Vetorecht, falls das åländische Parlament (,Lagting') die Grenzen der innenpolitischen Autonomie überschreiten sollte. Das åländische Parlament kann einen Repräsentanten in das finnische Parlament entsenden. Im Gegensatz zu Grönland und den Färöer Inseln wurde Åland mit Finnland Mitglied der Europäischen Union. Allerdings konnten steuerrechtliche Sonderregeln für diese Inselgruppe vertraglich festgeschrieben werden.

2 Das Symbol der nordischen politischen Zusammenarbeit ist der achtflügelige Schwan. Die Anzahl der Flügel repräsentiert also neben den fünf nordischen Territorialstaaten die autonomen Regionen Grönland, die Färöer Inseln sowie Åland (vgl. http://www.norden.org). 


\subsection{Parlamentarische Regierungssysteme und Monarchien - Dänemark, Norwegen, Schweden}

Die Monarchinnen und Monarchen des Nordens (vgl. Tabelle 2) erfüllen als staatsrechtliche Staatsoberhäupter nahezu ausschließlich repräsentative Aufgaben oder füllen zeremonielle Funktionen in den parlamentarischen Demokratien aus. So sind sie mitunter befugt, an den Kabinettssitzungen der nationalen Regierungen teilzunehmen. Auch besteht in allen nordischen Monarchien die Pflicht der Parlamente sowie Regierungen, die Königshäuser über die aktuellen Amtsgeschäfte zu informieren. Die nordischen Monarchien zeichnen sich ferner dadurch aus, dass sie im 20. Jahrhundert rasch eine Entpolitisierung ihrer Funktion akzeptierten, sich in der jüngeren Geschichte als erste Repräsentanten ihrer Nation weitgehend bewährten und was keineswegs selbstverständlich ist - die vorwiegend sozialdemokratischen Regierungspolitiken der Nachkriegszeit nicht unterminierten, sondern neutral begleiteten. Die integrative Wirkungsweise volksnaher Monarchien konnte jüngst in Norwegen beobachtet werden: Im Sommer 2011 reagierte das norwegische Königshaus emotional und sehr volksverbunden auf das Attentat in Oslo sowie das Massaker auf der Insel Utøya.

Tab. 2: Die skandinavischen Königinnen und Könige nach 1900

\begin{tabular}{lll}
\hline Dånemark & Norwegen & Schweden \\
\hline Christian IX (1863-1906) & Oskar II (1872-1905) & Oskar II (1872-1907) \\
Friedrich VIII (1906-1912) & Haakon VII (1905-1957) & Gustav V (1907-1950) \\
Christian X (1912-1947) & Olav V (1957-1991) & Gustav VI Adolf (1950-1973) \\
Friedrich IX (1947-1972) & Harald V (seit 1991) & Carl VI Gustaf (seit 1973) \\
Margrethe II (seit 1972) & & \\
\hline
\end{tabular}

Quelle: eigene Zusammenstellung

Das politische System in Dänemark besticht durch seine historische Kontinuität. Mit der 1848er Revolution wurde eine konstitutionelle Monarchie errichtet, in welcher der Monarch zwar noch beachtliche Kompetenzen besaß, er jedoch mit einem aus zwei Kammern bestehenden Parlament kooperieren musste. Im 20. Jahrhundert setzte sich die verfassungsrechtliche Traditionslinie ohne größere Zäsuren weiter fort. Nur drei offizielle Verfassungsänderungen (1915, 1920 sowie 1953) entwickelten die verfassungsrechtlichen Traditionen Dänemarks weiter. Mit der letzten Verfassungsrevision wurden die beiden parlamentarischen Kammern zu einer Kammer mit 179 Parlamentsmitgliedern zusammengefasst. ${ }^{3}$

3 Vgl. in englischer Sprache: http://www.thedanishparliament.dk/Democracy/The_Constitutional_ Act_of_Denmark.aspx, ebenso die deutsche Übersetzung: http://www.verfassungen.eu/dk/ (zuletzt aufgerufen 14.10.2013). 
Eine weitere Innovation der Verfassungsrevision von 1953 war die Einführung direktdemokratischer Elemente. Als Barriere gegen eine befürchtete uneingeschränkte parlamentarische Mehrheitsherrschaft wurde festgelegt, dass ein Drittel der Parlamentsmitglieder umstrittene Gesetzesentwürfe des Parlaments einem Referendum unterwerfen kann. Zwar sind bestimmte politische Bereiche (vor allem Haushalt und Steuern) einem solchen Verfahren entzogen. Dennoch stellt diese direktdemokratische Partizipationsmöglichkeit eine Besonderheit der dänischen Politik dar. Hinter der Schweiz, Italien und Irland kann sich Dänemark auf dem vierten Platz einer europäischen Rangliste direktdemokratischer Abstimmungen in der Nachkriegszeit behaupten. ${ }^{4}$ Allerdings gibt es in Dänemark keine Möglichkeit einer Volksinitiative.

Die Regierung wird von der Königin oder dem König ernannt. Ihre Existenz ist jedoch einzig vom Rückhalt im Parlament abhängig. Das Prinzip des negativen Parlamentarismus in Dänemark impliziert, dass ein Minister bzw. die Regierung dann zurilcktreten muss, wenn eine absolute Mehrheit des Parlaments dies fordert (Misstrauensvotum); Enthaltungen bei diesen Abstimmungen sichern allerdings den Machterhalt der Regierung ab. Die Regierung kann jederzeit durch die Einberufung von Neuwahlen einen solchen Schritt des Parlaments konterkarieren. Ferner impliziert dieses parlamentarische Prinzip, dass die Regierung keine aktive Mehrheit von Ja-Stimmen im Parlament hinter sich vereinigen muss, sondern auch durch Enthaltungen oder Absenzen geduldet werden kann. Diese Prinzipien ermöglichten die lange Tradition von Minderheitsregierungen in der dänischen Geschichte sowie die hohe Anzahl der Parlamentsauflösungen und vorzeitigen Neuwahlen (vgl. Tabelle 3 sowie hier wie im Folgenden ausführlicher Jochem 2012).

Die dänische Form des Regierens impliziert einen bedeutsamen Einfluss der parlamentarischen Opposition auf die Gesetzgebung, wie dies in allen Ländern mit Minderheitsregierungen der Fall ist. ${ }^{5}$ Tatsächlich ist das dänische Parlament ein dezidiertes Arbeitsparlament. Die Ausschussarbeit eröffnet den oppositionellen Fraktionen Mitwirkungsrechte, die über bloße Kontrollmöglichkeiten im Plenum hinausgehen. Durch die Tradition der Minderheitsregierungen, aber auch durch die seit $1973 \mathrm{zu}$ beobachtende Zerfaserung des dänischen Parteiensystems, sind Verhandlungen zwischen Regierung und oppositionellen Fraktionen vielschichtiger, unkalkulierbarer sowie zahlreicher geworden. So bestimmte die sozialdemokratische Opposition in der Åra Schlüter zentrale Aspekte dänischer Außenpolitik. Und bis 2011 hinterließ die rechtspopulistische Dänische Volkspartei als Oppositionspartei und parlamentarische Mehrheitsbeschafferin ihre programmatischen Spuren im Bereich der Rechts-, Sozialund Immigrationspolitik. Insofern kann von einer klar bestimmbaren Opposition in

4 Vergleiche Schmidt (2006: 360), Jochem (2012: 70). Eine aktuelle Datenbank direktdemokratischer Partizipationsmuster ist abrufbar unter: http://www.c2d.ch/index.php (Centre for Research on Direct Democracy) (zuletzt aufgerufen 14.10.2013).

5 Der klassische Beitrag zu den Formen, Vorzligen und Nachteilen von Minderheitsregierungen stammt von Strøm (1990). 
Dänemark nur schwerlich die Rede sein. $\mathrm{Zu}$ wechselhaft und verschwommen verlaufen - insbesondere nach 1982 - die Grenzen zwischen Regierung und Opposition im Gesetzgebungsprozess (Arter 2008, 193-255, Bergmann/Strøm 2011).

Tab. 3: Regierungen in Danemark seit 1980

\begin{tabular}{|c|c|c|c|c|}
\hline Premierminister & $\begin{array}{l}\text { Parteipolitische } \\
\text { Regierungs- } \\
\text { Zusammensetzung }\end{array}$ & $\begin{array}{l}\text { Zeitraum } \\
\text { (Monat/Jahr) }\end{array}$ & $\begin{array}{l}\text { Prozentualer } \\
\text { Sitzanteil der } \\
\text { Reglerungs- } \\
\text { parteien }\end{array}$ & $\begin{array}{l}\text { Prozentualer } \\
\text { Sitzantell der } \\
\text { stärksten Opposi- } \\
\text { tionspartel }\end{array}$ \\
\hline Jørgensen V(SD) & SD & $11 / 79-11 / 81$ & 38,9 & 12,6 \\
\hline Jørgensen VI (SD) & SD & $12 / 81-09 / 82$ & 33,7 & 14,9 \\
\hline Schluter I (KF) & $\mathrm{KF}, \mathrm{V}, \mathrm{CD}, \mathrm{KRF}$ & $10 / 82-01 / 84$ & 37,7 & 33,7 \\
\hline Schluter II (KF) & $\mathrm{KF}, \mathrm{V}, \mathrm{CD}, \mathrm{KRF}$ & $02 / 84-09 / 87$ & 44,0 & 32,0 \\
\hline Schluter III (KF) & KF, V, CD, KRF & $10 / 87-05 / 88$ & 40,0 & 30,9 \\
\hline Schluter IV (KF) & KF, V, RV & $06 / 88-12 / 90$ & 38,3 & 31,4 \\
\hline Schluter V (KF) & $\mathrm{KF}, \mathrm{V}$ & $01 / 91-01 / 93$ & 33,7 & 39,4 \\
\hline P.N. Rasmussen I (SD) & SD, CD, RV, KRF & $02 / 93-09 / 94$ & 50,9 & 17,1 \\
\hline P.N. Rasmussen II (SD) & SD, CD, RV & $10 / 94-12 / 96$ & 42,9 & 24,0 \\
\hline P.N. Rasmussen III (SD) & SD, RV & $01 / 97-03 / 98$ & 40,0 & 24,0 \\
\hline P.N. Rasmussen IV (SD) & SD, RV & 04/98-11/01 & 40,0 & 24,0 \\
\hline A.F. Rasmussen I $(\mathrm{N}$ & V, KF & $12 / 01-02 / 05$ & 41,1 & 29,7 \\
\hline A.F. Rasmussen II (V) & $\mathrm{V}, \mathrm{KF}$ & 03/05-11/07 & 40,0 & 26,9 \\
\hline A.F. Rasmussen III (V) & V, KF & $11 / 07-04 / 09$ & 36,6 & 25,7 \\
\hline L. L. Rasmussen (V) & V, KF & 04/09-09/11 & 36,6 & 25,7 \\
\hline H. Thorning-Schmidt (SD) & $S D, R V, S F$ & $10 / 11-$ & 43,0 & 26,3 \\
\hline
\end{tabular}

Abkürzungen der Parteien: SD = Socialdemokratiet/Sozialdemokratische Partel; V = Venstre/ Liberale Partei; $\mathrm{KF}=$ Konservative Folkeparti/Konservative Volkspartel; $R \mathrm{R}=$ Radlkale Venstre/ Radikal - Liberale Partel; RF = Denmarks Retsforbund/Danische Rechtspartei; $C D=$ Centrum Demokraterne/Zentrumsdemokraten; KRF = Kristelig Folkeparti/Christliche Volkspartel; $\mathbf{S F}=$ Socialistisk Folkeparti/Sozlalistische Volkspartei.

Quelle: elgene Zusammenstellung nach den Angaben der Regierungskanzlei des dänischen Ministerpräsidenten (http://www.stm.dk/Index/mainstart.asp/_p_7812.html) sowie Daten in http://www.parties-and-elections.eu/denmark.html (zuletzt aufgerufen 14.10.2013).

Das politische System Norwegens basiert auf einer Verfassung aus dem Jahr 1814. Seither wurden zahlreiche Modifikationen durchgefuhrt. Ähnlich wie in Dänemark entwickelte sich eine parlamentarische Demokratie mit starkem Parlament sowie einer starken Exekutive, das Königshaus erfüllt lediglich repräsentative und zeremonielle Funktionen. In Norwegen existieren hohe Hürden für Verfassungsreformen. Bei einer Anwesenheit von zwei Dritteln der Parlamentsmitglieder muss ein Quorum von mindestens zwei Dritteln der anwesenden Mitglieder für die anvisierte Verfassungsänderung stimmen. Zudem wird von der Verfassung eingefordert, dass erst das nächste Parlament diese Verfassungsänderung schlussendlich gutheißen kann.

Zentrale Gewalten des norwegischen Regierungssystems sind das Parlament (Stortinget'), der König sowie die Oberste Gerichtsbarkeit mit einem Verfassungsge? richt (,Norges Høyesterett ${ }^{\circ}$ ). In der Verfassung werden direktdemokratische Mecha* 
nismen nicht erwähnt. Es sind jedoch fakultative und konsultative Referenden auf Initiative des Parlaments möglich. Bis zum heutigen Tag erfolgten sechs Referenden, die allesamt die politische Geschichte des Landes prägten und in der Europapolitik Norwegens Zäsuren bewirkten (Jochem 2012: 75f.).

Das norwegische Parlament bestand bis ins Jahr 2009 aus einem ,qualifizierten“ unikameralen System. Ohne Anwendung einer Sperrklausel - es existiert eine 4Prozent-Hürde lediglich für die Berechnung von Ausgleichsmandaten - werden 169 Abgeordnete in das Parlament gewählt, wobei das Parlament nicht aufgelöst werden kann - eine Besonderheit Norwegens. Das bis 2009 wirksame ,qualifizierte' unikamerale Parlament bestand allerdings im Gegensatz zu heute aus zwei Versammlungen. Die norwegischen Verfassungsväter waren bestrebt, eine Art Oberhaus in das nationale Parlament zu integrieren, welches die Verfassungsmäßigkeit der Gesetzesinitiativen prüfen sollte. Nach der allgemeinen Wahl zum ,Stortinget‘ bestellten die Abgeordneten aus ihrer Mitte ein Viertel der Mitglieder proportional zum sogenannten ,Lagting;. Der verbleibende Rest des Parlaments bildete die zweite Kammer, den ,Odelsting;, welcher allein befugt war, Gesetzesinitiativen in den Prozess der parlamentarischen Beschlussfassung einzuspeisen. Der ,Lagting diente also quasi als erste Kammer. Erst wenn beide Kammern der Reform zustimmten, galt das Gesetz als vom Parlament verabschiedet. Hätte der ,Lagting' einer Reform nicht zugestimmt, dann hätte ein solches Veto durch eine gemeinsame Sitzung des vereinigten ,Storting' mit einem Zweidrittelbeschluss aufgehoben werden können.

Da jedoch beide Kammern auf einer gemeinsamen parlamentarischen Mehrheit beruhten und der ,Lagting proportional zu den Mehrheitsverhältnissen bestückt wurde, existierten praktisch keine Vetos dieser Kammer. Mit der Reform aus dem Jahr 2007 wurde diese Differenzierung des ,Storting' mit großer Mehrheit beseitigt. Seit den Parlamentswahlen im Jahre 2009 existiert also ein unikamerales Parlament in Norwegen. Der formale Gesetzgebungsweg wurde insofern verändert, als nun zwei Lesungen vorgesehen sind. Werden in der zweiten Lesung Veränderungen der Gesetzesinitiative vom Parlament beschlossen, wird eine abschließende dritte Lesung erforderlich.

In der norwegischen Nachkriegszeit dominieren parlamentarische Minderheitsregierungen (vgl. Tabelle 4). Ähnlich wie in Dänemark und Schweden existiert in Norwegen das Prinzip des negativen Parlamentarismus; seit 1960 vereinigten nur wenige Regierungen mehr als 50 Prozent der parlamentarischen Sitze auf sich. Seit dem Zweiten Weltkrieg dominierten bis ca. Mitte der 1960er-Jahre die norwegischen Sozialdemokraten die Regierungsgeschäfte. Seit dieser Zeit wechseln sich bürgerliche Koalitionsregierungen und Regierungen der sozialdemokratischen Partei Norwegens ab. Seit 2005 regierte die Sozialdemokratie erstmals in der Nachkriegszeit in einer offiziellen Koalition mit der Zentrumspartei sowie der linkssozialistischen Partei. Und erstmals seit den frühen 1980er-Jahren verfügen diese Regierungen über eine (wenn auch knappe) parlamentarische Mehrheit.

Die sozialdemokratisch geführte Koalition wurde bei der Wahl am 9. September 2013 abgewählt. Obgleich die ökonomischen Rahmendaten für Norwegen einzigartig 
positiv sind und sich die Koalition als durchaus produktive Regierung beweisen konnte, verlor sie bei den Wahlen die parlamentarische Mehrheit. Der Wahlkampf drehte sich um genuin wohlfahrtsstaatliche Themen, allerdings plädierte keine der norwegischen Parteien für Einschnitte ins soziale Netz. Insbesondere die Konservative Partei verfolgte in den vergangenen Jahren - wie ihre schwedische Schwesterpartei bereits zuvor - einen imposanten programmatischen Schwenk in die politische Mitte.

Eindeutige Gewinnerin der Wahl ist die konservative Rechtspartei $(\mathrm{H})$, die ihren Stimmen- und Sitzanteil deutlich erhöhen und die rechtspopulistische Fortschrittspartei als zweitgrößte Fraktion im Parlament ablösen konnte, die wiederum deutlich an Stimmen verlor. Die konservative Partei unter Führung von Erna Solberg strebt seit der Wahl die Bildung einer bürgerlichen Koalition bestehend aus Konservativer Partei $(\mathrm{H})$, rechtspopulistischer Fortschrittspartei (FRP), Christdemokraten (KRF) und Liberaler Partei (V) an. Die Regierungsbildung erwies sich als langwierig, da die Fortschrittspartei für die anderen bürgerlichen Parteien Probleme aufwirft. Letztlich konnte Erna Solberg lediglich eine aus den zwei stärksten bürgerlichen Parteien bestehende Minderheitsposition schmieden. Die oppositionellen Sozialdemokraten sind weiterhin stärkste Fraktion im norwegischen Parlament.

Tab. 4: Regierungen in Norwegen seit 1980

\begin{tabular}{|c|c|c|c|c|}
\hline $\begin{array}{l}\text { Premierminister } \\
\text { bzw. } \\
\text { Premierministerin }\end{array}$ & $\begin{array}{l}\text { Partelpolitlsche } \\
\text { Reglerungs- } \\
\text { zusammensetzung }\end{array}$ & $\begin{array}{l}\text { Zeitraum } \\
\text { (Monat/Jahr) }\end{array}$ & $\begin{array}{l}\text { Prozentualer Sitz- } \\
\text { anteil der Regie- } \\
\text { rungspartelen }\end{array}$ & $\begin{array}{l}\text { Prozentualer Sitzan- } \\
\text { teil der stärksten } \\
\text { Oppositionspartel }\end{array}$ \\
\hline Nordli II (DNA) & DNA & $10 / 77-01 / 81$ & 49,0 & 26,5 \\
\hline Brundtland I (DNA) & DNA & $02 / 81-09 / 81$ & 49,0 & 26,5 \\
\hline Willoch I (H) & H & $10 / 81-05 / 83$ & 34,8 & 41,9 \\
\hline Willoch II (H) & $\mathrm{H} ; \mathrm{KRF} ; \mathrm{SP}$ & $06 / 83-09 / 85$ & 51,6 & 41,9 \\
\hline Willoch III (H) & $\mathrm{H} ; \mathrm{KRF} ; \mathrm{SP}$ & $10 / 85-04 / 86$ & 40,1 & 45,2 \\
\hline Brundtland II (DNA) & DNA & $05 / 86-09 / 89$ & 45,2 & 31,8 \\
\hline Syse $(H)$ & H; KRF; SP & $10 / 89-10 / 90$ & 37,6 & 38,2 \\
\hline Brundtland III (DNA) & DNA & $11 / 90-08 / 93$ & 38,2 & 22,4 \\
\hline Brundtland IV (DNA) & DNA & $09 / 93-10 / 96$ & 40,6 & 19,4 \\
\hline Jagland (DNA) & DNA & $11 / 96-10 / 97$ & 40,6 & 19,4 \\
\hline Bondevik I (KRF) & KRF, SP, V & $11 / 97-03 / 00$ & 25,5 & 39,4 \\
\hline Stoltenberg I (DNA) & DNA & $04 / 00-10 / 01$ & 39,4 & 15,2 \\
\hline Bondevik II (KRF) & KRF, V, H & $11 / 01-10 / 05$ & 37,6 & 26,1 \\
\hline Stoltenberg II (DNA) & DNA, SV, SP & $10 / 05-09 / 09$ & 51,5 & 22,5 \\
\hline Stoltenberg III (DNA) & DNA, SV, SP & $10 / 09-09 / 13$ & 50,9 & 24,3 \\
\hline Solberg $(H)$ & H, FRP & $10 / 13-$ & 45,6 & 32,5 \\
\hline
\end{tabular}

Abkürzungen der Parteien: DNA = Det Norske Arbeiderparti/Norwegische Arbeiterpartei; SP = Senterpartlet/Zentrumspartei; $\mathrm{H}=\mathrm{H}$ øre/Konservative Partei; KRF = Kristelig Folkeparti/Christliche Volkspartei; V = Venstre/Liberale Partei; SV = Socialistisk Venstreparti/Linkssozialisten; FRP = Fremskrittspartiet (Fortschrittspartei).

Quelle: Informationen der norwegischen Regierung (http://www.regjeringen.no/en/thegovernment/previous-governments.html?id=85847) sowie Daten in http://www.parties-andelections.eu/norway.html (zuletzt aufgerufen 14.10.2013) 
Das politische System Schwedens beruht auf einer Verfassung, die maßgeblich aus vier Dokumenten besteht. Die sogenannte Regierungsform (,regeringsformen') stammt aus dem Jahre 1974 und beinhaltet die zentralen politischen Institutionen und Regeln. in dem aus dem Jahre 1810 stammenden Thronfolgegesetz (sucessionsordningen') werden Belange der Königsfolge reguliert. Die Pressefreiheitsverordnung (,tryckfrifhetsförordningen', 1766/ 1949) sowie das Gesetz zur freien Meinungsäußerung Gttrandefrihetsförordningen', 1991) regeln hingegen die entsprechenden Grundrechte und Grundfreiheiten des demokratischen Prozesses. Ergänzt werden diese zentralen Dokumente mit Verfassungsrang von der Rechtsordnung des Reichstags (,Riksdag(5ordningen') aus dem Jahre 1974. All diese Verfassungstexte basieren auf einem urpprünglichen Verfassungstext aus dem Jahr 1809. Die damalige Verfassungskrise (und militärische Niederlagen) führte dazu, dass König Gustav IV Adolf erstmals in seiner absolutistischen Machtfülle eingeschränkt wurde.

Das Machtzentrum Schwedens liegt im Reichstag sowie der aus ihm hervorgehenden Regierung. Als Staatsoberhaupt wird in der Verfassung zwar ausgeführt, dass ein König (oder eine Königin) erste Person im Staate sei, allerdings wird ebenso betont, dass die Monarchie über keinerlei politische Macht verfüge. Weder ist im Kriegsfall der Monarch als oberster Befehlshaber vorgesehen, noch hat der König irgendwelche Rechte auf Information durch die Regierung bzw. Teilnahme an Kabinettssitzungen. Das schwedische Königshaus ist somit explizit auf rein repräsentative Aufgaben beschränkt.

Das schwedische Parlament (,Riksdag') besteht seit 1971 aus einer Kammer. Die (seit 1976) 349 Abgeordneten werden in allgemeinen Wahlen bestimmt, wobei landesweit eine 4-Prozent Sperrklausel existiert. Seit 1994 wurde die Legislaturperiode von drei auf vier Jahre ausgeweitet. Hierfür war der breite politische Konsens maßgebend, dass drei Jahre zu wenig Zeit seien, um der Regierung Gestaltungschancen zu eröffnen, bevor der erneute Wahlkampf ein zielgerichtetes Regieren erschwere. Der schwedische Reichstag kann als dezidiertes Arbeitsparlament verstanden werden. Eine Vielzahl von Ausschüssen strukturiert den Gesetzgebungsprozess. In diesen Ausschüssen werden mitunter Sachkompromisse verfolgt, die unter den Bedingungen von Minderheitsregierungen das Regieren erst ermöglichen. Ebenso auffallend ist die hohe Fraktionsdisziplin bei allen im ,Riksdag' vertretenen politischen Parteien.

Die schwedischen Regierungen sind einzig vom Vertrauen und der politischen Unterstützung des Reichstags abhängig. Das Prinzip des negativen Parlamentarismus impliziert auch in Schweden, dass der Regierungschef nicht eine absolute Mehrheit für sich im Parlament erlangen muss. Es darf nur nicht die Mehrheit gegen ihn oder sie stimmen. Nach erfolgreicher Wahl bestimmt der Ministerpräsident seine Kabinettsmitglieder ohne erneute Bestätigung durch das Parlament.

Wie in den Nachbarländern dominieren Minderheitsregierungen die schwedische Nachkriegsgeschichte (vgl. Tabelle 5). Die Regierungsgeschichte nach dem Zweiten Weltkrieg wird eindeutig von der sozialdemokratischen Partei Schwedens dominiert. Diese hegemoniale Machtstellung wurde zwischen 1976 und 1982, zwischen 1991 und 
1994 sowie seit 2006 unterbrochen. Die gegenwärtige bürgerliche Koalition stellt eine programmatisch kohärente Allianz dar, bestehend aus der Konservativen Partel, der Zentrumspartei, der liberalen Volkspartei sowie der kleinen Christdemokratischen Partei (Jochem 2011a).

Tab. 5: Reglerungen in Schweden seit 1980

\begin{tabular}{lllll}
\hline Premierminister & $\begin{array}{l}\text { Reglerungs- } \\
\text { zusammenset- } \\
\text { zung }\end{array}$ & $\begin{array}{l}\text { Zeitraum } \\
\text { (Monat//ahr) }\end{array}$ & $\begin{array}{l}\text { Prozentualer Sitz- } \\
\text { anteil der Regie- } \\
\text { rungsparteien }\end{array}$ & $\begin{array}{l}\text { Prozentualer Sitz- } \\
\text { antell der stärksten } \\
\text { Oppositionspartel }\end{array}$ \\
\hline Fäldin II (C) & C; FP; M & $10 / 79-04 / 81$ & 50,1 & 44,1 \\
Fulldin III (C) & C; FP & $05 / 81-09 / 82$ & 29,2 & 44,1 \\
Palme IV (SAP) & SAP & $10 / 82-09 / 85$ & 47,6 & 24,6 \\
Palme V (SAP) & SAP & $10 / 85-02 / 86$ & 45,6 & 21,8 \\
Carlsson I (SAP) & SAP & $03 / 86-09 / 88$ & 45,6 & 21,8 \\
Carlsson II (SAP) & SAP & $10 / 88-09 / 91$ & 44,7 & 18,9 \\
Bildt (M) & M; FP; C; KDS & $10 / 91-09 / 94$ & 48,7 & 39,5 \\
Carlsson III (SAP) & SAP & $10 / 94-03 / 96$ & 46,1 & 22,9 \\
Persson I (SAP) & SAP & $04 / 96-09 / 98$ & 46,1 & 22,9 \\
Persson II (SAP) & SAP & $10 / 98-09 / 02$ & 37,5 & 23,5 \\
Persson III (SAP) & SAP & $10 / 02-09 / 06$ & 41,3 & 15,8 \\
Reinfeldt I (M) & M, C, KDS, FP & $10 / 06-09 / 10$ & 51,0 & 37,2 \\
Reinfeldt II (M) & M, C, KDS, FP & $10 / 10-$ & 49,6 & 32,1 \\
\hline
\end{tabular}

Abkurzungen der Partelen: SAP = Soclaldemokratiska Arbetarepartiet/Sozlaldemokratische Arbeiterpartei; $C=$ Centerpartiet/Zentrumspartel; $F P=$ Folkpartie /Liberale Volkspartei; $M=$ Moderaterna/Konservative Partel; KDS = Kristen Demokratisk Samling/Christdemokraten Quelle: Jahn (2009) sowie elgene Berechnung nach Informationen der schwedischen Regierung (http://www.regeringen.se/sb/d/4393) sowie Daten aus http://www.partles-andelections.eu/sweden.html (zuletzt aufgerufen 14.10.2013).

\subsection{Semi-Präsidentielle Regierungssysteme im Wandel - Finnland und Island}

Die politischen Systeme Islands und Finnlands werden nach gängigen Klassifikationen dem Semi-Präsidentialismus zugeordnet. Die dortigen Präsidenten werden direkt vom Volk gewählt und konnten über lange Etappen der Nachkriegsgeschichte aktiv und mit großer Vetomacht die Außen-, aber auch die Innenpolitik mitgestalten. Beiden Ländern gemein ist in der jüngsten Vergangenheit der Trend hin zur Stärkung parlamentarischer Prinzipien im demokratischen Institutionengefüge.

Das politische System Finnlands folgte von 1919 bis 1946 eindeutig parlamentarischen Prinzipien. Durch die prekäre weltpolitische Lage Finnlands zwischen den beiden Machtblöcken nach dem Zweiten Weltkrieg sowie aufgrund der wechselhaften Beziehungen des Landes zur UdSSR entwickelte sich nach 1946 eine finnische Form 
des Semi-Präsidentialismus (als auch eine besondere Form ausgleichender Außenpolitik, die mitunter als „Finnlandisierung“ pejorativ umschrieben wird).

Insbesondere Urho Kekkonen, Präsident von 1956 bis 1982 (vgl. Tabelle 6), dominierte im Zeitalter des Kalten Krieges mit seiner mächtigen Präsidentschaft die finnische Außen- und Innenpolitik. Kekkonen, aber bereits auch Paasikivi, füllten diese mächtige Rolle in der finnischen Politik charismatisch aus. Die alte Verfassung ermöglichte dem Präsidenten innenpolitisch ein Vetorecht gegen Regierung und Parlament. Und beide Präsidenten machten unmissverständlich klar, dass sie sich dieses Instrumentes auch bedienen würden. In dieser Zeit waren die finnischen Regierungen oft von kurzer Dauer (vgl. Tabelle 7), insbesondere Kekkonen löste wiederholt Parlament oder Regierungen auf. Die starke Rolle des Präsidenten, so lautet der Tenor in der Literatur, diente als Stabilitätsfaktor für das gesamte politissche System in dieser politisch prekären Lage (Arter 1987, 2008).

Tab. 6: Finnlands Prăsidenten

\begin{tabular}{lll}
\hline Præ̋sident/Präsidentin & Präsidentschaft & Partei \\
\hline K.J. Ståhlberg & $1919-1925$ & Jungfinnen \\
Lauri Dristian Relander & $1925-1931$ & KESK \\
Pehr Evind Svinhufvud & $1931-1937$ & KOK \\
Kyð̋sti Kallio & $1937-1940$ & KESK \\
Risto Ryti & $1940-1944$ & Nationalliberale Partei \\
C.G. Mannerheim & $1944-1946$ & Parteilos \\
Juho Kusti Paasikivi & $1946-1956$ & KOK \\
Urho Kekkonen & $1956-1982$ & KESK \\
Mauno Koivisto & $1982-1994$ & SDP \\
Martti Ahtisaari & $1994-2000$ & SDP \\
Tarja Halonen & $2000-2012$ & SDP \\
Saull NIInistő & $2012-$ & KOK \\
\hline
\end{tabular}

Anmerkungen: Bei der sich als ,Jungfinne' bezeichnenden Partel handelt es sich um eine liberale Absplitterung von der konservativ-nationalen Finnischen Partel (Altfinnen'), SDP $=$ Sosialdemokraattinen Puo-lue/Sozialdemokratische Partei; KESK = Suomen Keskusta/Zentrumspartel; KOK = Kansallinen Kokoomus/Nationale Sammlungspartei.

Quelle: http://www.presidenttl.fi/public/default.aspx?nodeid=44829\&contentlan=3\&culture=sv$\mathrm{Fl}$, http://www.presidentti.fi/public/default.aspx?culture=sv-Fl\&contentlan=3 (zuletzt aufgerufen 14.10.2013)

Die Verfassungsreform aus dem Jahr 2000 hat nicht nur die verschiedenen Verfassungstexte in einem ,Grundgesetz' vereint. ${ }^{6}$ Die Reform hat zudem die Rolle des Präsidenten neu justiert und die ,Parlamentarisierung' Finnlands rechtlich befestigt. Die neue Verfassung gliedert sich - wie in Deutschland - in einen allgemeinen Teil der

6 Der aktuelle Verfassungstext ist auch in deutscher Sprache abrufbar unter: http://www.om.f/ 21910.htm (zuletzt aufgerufen 14.10.2013). 
Grundrechte sowie einen staatsorganischen Teil, in welchem die Funktionsweise der Staatsorgane sowie die grundlegenden politischen Spielregeln festgelegt sind. Als neue Schwerpunkte der finnischen Verfassung können folgende Punkte festgehalten werden:

Erstens wurde in vielen Belangen die Position des Präsidenten geschwächt. Wäh. rend die Präsidentin oder der Präsident gemäß der alten Verfassung ein blockierendes Veto im Gesetzgebungsprozess geltend machen konnte, steht ihr oder ihm heute nur noch ein aufschiebendes Vetorecht zu. Zweitens ist zwar die Außenpolitik weiterhin Kerndomäne des Präsidentenamts. Allerdings wird in der neuen Verfassung erstmals festgeschrieben, dass internationale Verträge vom Parlament gebilligt werden müssen. In der Außenpolitik kann der Präsident also nicht mehr am Parlament vorbei regieren. Hierbei ist auch zu erwähnen, dass die EU-Politik explizit und eng an das Parlament geknüpft wurde. Im sogenannten ,Großen Rat" (Suuri Valiokunta'), einem parlamentarischen Ausschuss, ist die Regierung verpflichtet, vor Tagungen des Europäischen Rates die Parlamentarier umfassend und rechtzeitig über Belange der Europapolitik zu informieren. Drittens - und mit entscheidender Wirkung - kann der Präsident unter der neuen Verfassung nicht mehr das Parlament auflösen oder die Regierung entlassen. In der Verfassung wird explizit festgehalten, dass der Präsident die vom Parlament gewählten Minister und Ministerpräsidenten nur noch ernennt. Damit hat sich das politische System Finnlands hinsichtlich der zentralen politischen Spielregeln deutlich verändert.

Das finnische Parlament (,Eduskunta') ging 1906 aus einem Vierkammernparlament hervor und hat seither nur eine Kammer mit 200 Abgeordneten.' Im Parlament arbeiten verschiedene Ausschüsse am Gesetzgebungsverfahren mit. Insbesondere der ,Große Rat' nimmt eine wichtige Funktion ein. Seit Gründung der Eduskunta diente dieser Ausschuss quasi als zweite Kammer, in der alle Gesetzesentwürfe nochmals aus verfassungsrechtlicher Perspektive geprüft werden. Heute besitzt dieser Ausschuss insbesondere in der EU-Politik Finnlands eine zentrale Bedeutung.

Die 200 Mitglieder des finnischen Parlaments werden in geheimer und direkter Wahl nach dem Verhältniswahlrecht ohne Sperrklausel gewählt. Der parlamentarische Vertreter Ålands wird hingegen nach dem Mehrheitswahlrecht ermittelt. Bis 1955 erstreckte sich die Legislaturperiode auf drei Jahre, seither - sofern das Parlament nicht vorzeitig aufgelöst wurde - auf vier Jahre. Per Gesetz ist der dritte Sonntag im März als Wahltag festgelegt.

Mit der Verfassungsreform aus dem Jahr 2000 wurde nicht nur das Parlament, sondern auch die nationale Regierung im politischen Prozess gestärkt. Vor dieser Reform war die Position der Regierung eher schwach. Hierfür war erstens die bereits erwähnte dominante Stellung des finnischen Präsidenten verantwortlich. Der schottische

7 Vergleiche für aktuelle sowie historische Informationen zum finnischen Parlament: www.eduskuntafl (zuletzt aufgerufen 14.10.2013). 
Finnlandexperte David Arter hat die Macht der Regierung vor der Verfassungsreform folgendermaßen umschrieben: „the foremost duty of the government is to execute presidential decisions“ (Arter 1987: 50). Zweitens weist Finnland ein stark ausgeprägtes Mehrparteiensystem auf, was Koalitionsbildungen erschwert. Drittens schließlich existierten in der alten Verfassung zahlreiche Klauseln, die in bestimmten Sachthemen qualifizierte Mehrheiten (in der Regel 2/3 der Sitze) einforderten. In vielen ökonomisch und steuerpolitisch relevanten Belangen führte dies zur finnischen Besonderheit, dass breite parlamentarische Mehrheiten für die Gesetzgebung unerlässlich waren. In der Konsequenz implizierte dies, dass die finnischen Parteien $\mathrm{zu}$ Verhandlungen über Partei- und Blockgrenzen gezwungen wurden. Nicht zuletzt das jährliche Budget erforderte eine solche qualifizierte Mehrheit und nicht selten waren die Budgetverhandlungen in Finnland langwierig und mündeten oft in Großen Koalitionen.

Der Trend hin zu offiziellen Großen Koalitionen setzte seit den 1960er-Jahren ein. Mit der Schwächung des Präsidenten nach 1982 wurden dann verstärkt offizielle Große Koalitionen zur Absicherung parlamentarischer Mehrheiten eingegangen. Die parlamentarischen Mehrheiten der Großen Koalitionen schwanden in der letzten Dekade. Die gegenwärtige Große Koalition unter der Führung des konservativen Premierministers Jyrki Katainen (KOK) kann jedoch mit über 60 Prozent der parlamentarischen Sitze wieder eine deutliche Mehrheit hinter sich vereinigen - allerdings ist die Anzahl der Regierungsparteien auf sechs angestiegen (vgl. Tabelle 7).

Die finnische Regierungsgeschichte weist folgende Besonderheiten auf. Erstens handelt es sich in den allermeisten Jahren der Nachkriegsgeschichte um Koalitionsregierungen. Seit den 1970er-Jahren zumeist um Große Koalitionen, die bis zu 70 Prozent der Sitze auf sich vereinigten. Eine besondere Stellung nehmen zweitens die finnischen Kommunisten und späteren Linkssozialisten ein. Während in den anderen nordischen Ländern diese Parteien meist nur in der Opposition waren oder als (mehr oder wenig passive) Mehrheitsbeschaffer für sozialdemokratische Minderheitsregierungen dienten (wie zum Beispiel in Schweden), hatten sie in Finnland einen größeren politischen Einfluss auf Regierungsebene. Drittens ist die Zahl der Regierungen sehr hoch. Die kurzen Amtszeiten finnischer Regierungen können historisch auf die ehemals mächtige Rolle des Präsidenten sowie die Unwägbarkeiten von Koalitionsregierungen mit mehreren Partnern zurückgeführt werden. Viertens ist zu notieren, dass noch vor der rot-grïnen Regierungszeit in Deutschland die finnischen Grünen den Sprung in die nationale Regierung schafften. Fünftens dominieren drei Parteien die Regierungsgeschäfte der finnischen Nachkriegszeit: Die Zentrumspartei, die Sozialdemokraten sowie die liberale Partei der schwedischsprachigen Minderheit in Schweden, die ,Svenska Folkpartiet' (SFP). Diese Parteien sind in der Mehrzahl der nationalen Regierungen vertreten. Erst in jüngster Vergangenheit (nach 1987) konnte die Konservative Partei Finnlands (KOK) erstmals in der Nachkriegszeit in eine nationale Regierung einziehen und in jenem Jahr auch erstmals in der Nachkriegsgeschichte den Regierungschef stellen. Die gegenwärtige Regierung wird nach langer Zeit erneut von einem konservativen Regierungschef geleitet, von Jyrki Katainen. 
Tab. 7: Regierungen in Finnland seit 1980

\begin{tabular}{|c|c|c|c|c|}
\hline Premierminister & $\begin{array}{l}\text { Parteipolitische Regie- } \\
\text { rungszusammenset- } \\
\text { zung }\end{array}$ & $\begin{array}{l}\text { Zeitraum } \\
\text { (Monat/Jahr) }\end{array}$ & $\begin{array}{l}\text { Prozentualer } \\
\text { Sitzantell der } \\
\text { stärksten Oppo- } \\
\text { sltionspartel }\end{array}$ & $\begin{array}{l}\text { Prozentualer } \\
\text { Sitzanteil der } \\
\text { Regierungs- } \\
\text { Partelen }\end{array}$ \\
\hline Koivisto II (SDP) & $\begin{array}{l}\text { SDP; KESK; SFP; } \\
\text { Volk.dem }\end{array}$ & $05 / 79-01 / 82$ & 23,5 & 66,5 \\
\hline Sorsa IV (SDP) & $\begin{array}{l}\text { SDP; KESK; SFP; } \\
\text { Volk.dem. }\end{array}$ & $02 / 82-12 / 82$ & 23,5 & 66,5 \\
\hline Sorsa V (SDP) & SDP; KESK; SFP & $01 / 83-03 / 83$ & 23,5 & 49,0 \\
\hline Sorsa VI (SDP) & SDP; KESK; SFP; SMP & $04 / 83-03 / 87$ & 22,0 & 61,5 \\
\hline Holkeri (KOK) & KOK; SDP; SFP; SMP & $04 / 87-03 / 91$ & 20,0 & 65,5 \\
\hline Aho I (KESK) & KESK; KOK; SFP; SKL & $04 / 91-06 / 94$ & 24,0 & 57,5 \\
\hline Aho II (KESK) & KESK; KOK; SFP & $07 / 94-03 / 95$ & 24,0 & 53,5 \\
\hline Lipponen I (SDP) & $\begin{array}{l}\text { SDP, KOK, SFP, VIHR, } \\
\text { VAS }\end{array}$ & $04 / 95-03 / 99$ & 22,0 & 72,5 \\
\hline Lipponen II (SDP) & $\begin{array}{l}\text { SDP, KOK, SFP, VIHR, } \\
\text { VAS }\end{array}$ & $04 / 99-04 / 02$ & 24,0 & 70,0 \\
\hline Lipponen III (SDP) & SDP, KOK, SFP, VAS & $05 / 02-03 / 03$ & 24,0 & 64,5 \\
\hline jăătteenmăki (KESK) & KESK, SDP, SFP & $04 / 03-06 / 03$ & 20,0 & 58,5 \\
\hline Vanhanen I (KESK) & KESK, SDP, SFP & $07 / 03-04 / 07$ & 20,0 & 58,5 \\
\hline Vanhanen II (KESK) & KESK, KOK, VIHR, SFP & $05 / 07-06 / 10$ & 22,5 & 58,4 \\
\hline Kiviniemi (KESK) & KESK, KOK, VIHR, SFP & $07 / 10-05 / 11$ & 22,5 & 58,4 \\
\hline Katainen (KOK) & $\begin{array}{l}\text { KOK, SDP, VAS, VIHR, } \\
\text { SFP, KD }\end{array}$ & $06 / 11-$ & 19,5 & 62,5 \\
\hline
\end{tabular}

Abkurzungen der Parteien: Volk.dem. $=$ Volksdemokraten; SDP $=$ Sosialdemokraattinen Puolue/Sozialdemokratische Partei; KESK = Suomen Keskusta/Zentrumspartel; SFP = Svenska Folkpartiet/Schwedische Volkspartel; KOK = Kansallinen Kokoomus/Nationale Sammlungspartei; SMP = Suomen Maaseudun Puolue/Finnische Landvolk Partei; SKL = Suomen Kritillinen Liitto/Christlicher Bund; VAS = Vasemmisto Liitto/Linksallianz; VIHR $=$ Vihreă Llitto $/$ Grune Allianz, KD = Suomen Kristillisdemokraatit/Christdemokraten.

Quellen: Berechnungen aufbauend auf Informationen der finnischen Regierung (http://valtioneuvosto.fi/tietoa-valtioneuvostosta/hallitukset/vuodesta-1917/en.jsp) sowie auf Daten aus http://www.parties-and-elections.eu/finland.html (zuletzt aufgerufen 14.10.2013)

Das politische System Finnlands hat sich in den vergangenen Dekaden gewandelt. Die ,Parlamentarisierung' der finnischen Politik wurde mit der Verfassungsreform aus dem Jahre 2000 auch in Rechtsform festgeschrieben. Zentrale Machtbefugnisse des Präsidentenamts wurden aufgehoben; allerdings schwelt weiterhin ein latenter Konflikt zwischen dem Präsidentenamt und den Regierungen über die präzise Aufteilung der außenpolitischen Kompetenzen. Eine erneute Verfassungsrevision soll in Zukunft die Aufgabenverteilung zwischen Präsidentin und Regierung präziser justieren. Mit dem Wegfall qualitativer Mehrheitsanforderungen im finnischen Gesetzgebungsprozess hat sich der Wettbewerbscharakter der finnischen Innenpolitik verstärkt. Offizjelle Große Koalitionen werden nicht mehr in dem Maße angestrebt, wie dies früher der Fall war. Allerdings ist die pragmatische Koalitionsfähigkeit finnischer Parteien au- 
ßerordentlich groß, dies kann nicht zuletzt an der gegenwärtigen Großen Koalition abgelesen werden.

Die Verfassung Islands ähnelt aufgrund historischer Verbindungen in vielen Punkten der dänischen Verfassung. ${ }^{8}$ Mit der nationalen Unabhängigkeit und dem Ausscheiden aus dem dänischen Königreich (1944) wurde der (direkt vom Volk gewählte) isländische Präsident quasi als Ersatz für den dänischen König in die Verfassung aufgenommen. Insofern verfügt er über vielfältige Kompetenzen, mittels denen er zusammen mit dem Parlament die Gesetzgebung vollzieht. Er ist allein für die Regierungsbildung verantwortlich und weist nach dem Verfassungstext den Ministern der nationalen Regierung ihre Aufgaben zu (Artikel 15 der isländischen Verfassung).

In der Realität haben die isländischen Präsidenten den Verfassungstext teilweise ignoriert und eine davon abweichende Verfassungswirklichkeit ins Leben gerufen. Zwar ist der isländische Präsident im Prozess der Regierungsbildung involviert, allerdings weniger als ,Königsmacher' sondern vielmehr als ,Moderator'. Ihm obliegt de jure die Macht, einzelne Minister zu berufen und abzuberufen sowie das nationale Parlament aufzulösen. Damit nimmt der vom Volk gewählte Präsident laut Verfassung eine zentrale Stellung im politischen System ein. Aber in der Verfassungswirklichkeit zeigt sich, dass die maßgeblichen politischen Verhandlungen im Parlament stattfinden und sich die isländischen Präsidenten diesen Ergebnissen fügen. Tatsächlich wird Island in der Literatur aufgrund seiner effektiven Verfassungswirklichkeit meist als ,semi-präsidentielle' Demokratie bezeichnet. Arend Lijphart kommt in diesem Punkt zu dem Ergebnis, dass das formal präsidentielle Regierungssystem Islands eigentlich (ähnlich wie in Ǒsterreich, Irland oder Portugal nach 1982) weitestgehend wie ein parlamentarisches System funktioniere (Lijphart 1999: 121).

Der isländische Präsident ist in seiner realen Funktion weitgehend auf Repräsentation ausgerichtet. Allerdings ist er oder sie auch eine zentrale Person im öffentlichen Leben und kann aufgrund seiner Wortmeldungen die politische Debatte prägen. Welche Symbolkraft diesem Amt innewohnt, offenbarte sich nach 1980, als Vigdis Finnbogadóttir zur ersten Präsidentin gewählt wurde (vgl. Tabelle 8). Ihre Amtszeit lenkte die internationale Aufmerksamkeit auf die Insel im Nordpazifik und Vigdís Finnbogadóttir konnte das Amt so geschickt mit Leben füllen, dass sie vier Jahre später mit fast $95 \%$ der Stimmen im Amt bestätigt wurde. Insgesamt amtierte sie 16 Jahre als Präsidentin der isländischen Republik. Olafur Ragnar Grimson übernahm das Präsidentenamt im Jahr 1996 und kann gegenwärtig auf eine bereits längere Amtszeit als Finnbogadóttir zurückblicken. Die politische Rolle des Präsidenten wurde von Olafur Ragnar Grimson in der isländischen Finanzkrise nach 2008 extrem ausgeweitet. So nahm er nicht nur auf die öffentliche Diskussion im Zusammenhang mit den Verhandlungen zur Kom-

8 Die Verfassung Islands ist in englischer Sprache im Internet unter http://www.government.is/ constitution/ abrufbar, in deutscher Sprache unter http://www.verfassungen.eu/is/index.htm einsehbar (zuletzt aufgerufen 14.10.2013). 
pensation ausländischer Gläubiger (,Icesave') direkt Stellung, sondern machte auch aus seiner ablehnenden Haltung gegenüber einer Verfassungsrevision keinen Hehl. Letztlich verweigerte er einem Abkommen der isländischen Regierung mit den Regierungen der Niederlande und Großbritanniens zur Kompensation ausländischer Gläublger seine Unterschrift, was zwei Referenden nach sich zog. In beiden Referenden unterlag die isländische Regierung und dieser außenpolitische Streitfall gelangte bis zum Gerichtshof der EFTA, wo letztlich die Position des Präsidenten gestärkt wurde.

Tab. 8: Die Prăsidenten Islands

\begin{tabular}{ll}
\hline Name & Amtszeit \\
\hline Sveinn Björnsson & $1944-1952$ \\
Ásgeir Ásgeirsson & $1952-1968$ \\
Kristján Eldjárn & $1968-1980$ \\
Vigdís Finnbogad6ttir & $1980-1996$ \\
Ólafur Ragnar Grímsson & $1996-$ \\
\hline Quelle: http://english.forseti.is/ (zuletzt aufgerufen 14.10.2013)
\end{tabular}

Das faktische Zentrum der Macht stellt in Island allerdings in der Regel das Parlament und die aus ihr hervorgehende Exekutive dar. Der ,Alpingi' (Althingi) ${ }^{9}$ ist eines der ältesten Parlamente der Welt, es wurde bereits im Jahre 930 gegründet und erlebte eine nahezu ununterbrochene historische Kontinuität - war allerdings in den frühen Jahren kein demokratisches Parlament nach heutigem Verständnis. Das dänische Königtum schaffte den Althingi im Jahre 1800 ab, musste ihn jedoch 1845 auf Druck des isländischen Volkes wieder zulassen. Allerdings besaß das Parlament danach einzig eine beratende Funktion und verfügte über keine effizienten Machtmittel gegenüber Regierung und dänischem König.

Erst im Jahre 1874 erlangte das Parlament erste gesetzgebende Funktionen. Der dänische König räumte eine gemeinsame Gesetzgebung zwischen Krone und Althingi in den rein auf isländische Belange ausgerichteten Gesetzgebungsverfahren ein. Mit der von der dänischen Krone im Jahre 1903 (in Grenzen) zugestandenen isländischen Autonomie erfuhr das isländische Parlament eine weitere deutliche Aufwertung. Im Jahre 1915 wurde das allgemeine Wahlrecht gleichzeitig für Männer und Frauen eingefuihrt, im Jahre 1922 wählten die Isländer die erste Frau in das nationale Parlament. Mit der nationalen Unabhängigkeit (am 17. Juni 1944) wurde das Parlament schließlich das faktische Zentrum der isländischen Politik. Graduell wurde das Wahlalter auf heute 18 Jahre abgesenkt. Die letzte große Parlamentsreform fand im Jahr 1991 statt. Island folgte hierbei dem dänischen und schwedischen Beispiel und vereinigte beide Kammern des Parlaments. Heute sitzen im unikameralen isländischen Parlament 63 Abgeordne-

9 Vgl. die Homepage des isländischen Parlaments http://www.althingl.is/vefur/upplens.html (zuletzt aufgerufen 14.10.2013). 
te, die in einem vierjährigen Rhythmus in freier, gleicher und geheimer Wahl gewählt werden. Es existiert keine Sperrklausel im proportionalen Wahlrecht Islands.

Die zweite Zentrale des isländischen Staates ist die nationale Regierung. Entgegen dem skandinavischen Trend sind Minderheitsregierungen in Island (ebenso wie in Finnland nach 1960) die Ausnahme. Die konservativ-liberale Unabhängigkeitspartei, die sozialdemokratische Partei sowie die Fortschrittspartei als Partei der agrarischliberalen Mitte dominieren die Koalitionsregierungen der Nachkriegszeit. Einzelne Minister bzw. die gesamte Regierung sind vom Vertrauen der Mehrheit im Parlament abhängig - und nicht vom isländischen Präsidenten. Misstrauensvoten kommen in der isländischen Geschichte selten vor. Dies hängt damit zusammen, dass in Krisensituationen, in denen die parlamentarische Mehrheit der Regierung gefährdet ist, die Exekutive (formal der Präsident) das Recht hat, das Parlament aufzulösen und Neuwahlen einzuberufen. Dies erklärt die (ebenso wie in Dänemark und Finnland) große Anzahl von Regierungen in der isländischen Nachkriegszeit.

Im Gesetzgebungsprozess liegt die Initiative bei der Regierung. Das in 12 Ausschüsse gegliederte Parlament behandelt Gesetzesinitiativen in drei Lesungen; die Rechtskräftigkeit wird dann vom Präsidenten der Republik verkündet. Zwar liegen nach Verfassung die außenpolitischen Vertragskompetenzen einzig beim Präsidenten, in der Realität wird die Außenpolitik allerdings von der Regierung betrieben.

Etwaige Verfassungsänderungen sind mit einer unbedingten Neuwahl des Parlaments verbunden. Wenn die absolute Mehrheit im Parlament eine Verfassungsänderung verabschiedet, wird das Parlament aufgelöst und Neuwahlen werden einberufen. Bestätigt das neu gewählte Parlament den Beschluss des Vorgängerparlaments, dann ist die Verfassungsänderung angenommen und wird vom Präsidenten mit Rechtskraft versehen. Verfassungsänderungen in Bezug auf die isländische Staatskirche bedürfen eines Referendums. Ebenso soll das Volk direkt abstimmen, wenn der Präsident sich weigern sollte, Gesetzesvorlagen des Parlaments zu verabschieden oder wenn der Präsident vom Parlament abgesetzt werden soll. Die Loslösung vom dänischen Königreich wurde 1944 mithilfe eines landesweiten Referendums herbeigeführt, ebenso erfolgte im Herbst 2012 ein konsultatives Referendum zur geplanten Verfassungsreform. Erstmals kam es 2010 und 2011 zu Referenden, da sich der Präsident weigerte, Entschädigungsgesetze im Zusammenhang mit dem Konkurs der isländischen Onlinebank icesave zu unterzeichnen (Gylfason 2012; Jochem 2013c).

Die Nachkriegsgeschichte Islands wird insgesamt von der Hegemonie der Unabhängigkeitspartei Islands charakterisiert. Diese liberal-konservative Partei war nicht nur fast ohne Ausnahmen seit 1960 in den Regierungen vertreten. Zudem war sie auch bis in die jüngste Zeit die dominante Partei im isländischen Parteienwettbewerb. Die Sozialdemokraten, sonst in den nordischen Ländern stets bedeutsame politische Akteure, konnten in Island nie die Hegemonie der Unabhängigkeitspartei sowie der in jüngerer Vergangenheit ebenso dominanten Fortschrittspartei herausfordern. Erst mit den politischen Erschütterungen im Zusammenhang mit der globalen Finanzkrise gelang es der isländischen Sozialdemokratie (in Koalition mit der grün-sozialistischen 
Partei) die Regierungsgeschäfte zu übernehmen und erstmals seit 1979 wieder die Ministerpräsidentin zu stellen (vgl. Tabelle 9). ${ }^{10}$

Tab. 9: Regierungen in Island seit 1980

\begin{tabular}{|c|c|c|c|c|}
\hline Premierminister & $\begin{array}{l}\text { Parteipolitische } \\
\text { Regierungs- } \\
\text { zusammensetzung }\end{array}$ & $\begin{array}{l}\text { Zeltraum } \\
\text { (Monat//ahr) }\end{array}$ & $\begin{array}{l}\text { Prozentualer } \\
\text { Sitzanteil der } \\
\text { Regierungs- } \\
\text { partelen }\end{array}$ & $\begin{array}{l}\text { Prozentualer } \\
\text { Sitzanteil der } \\
\text { stärksten Oppo- } \\
\text { sitionspartel }\end{array}$ \\
\hline Gröndal (AF) & AF & $11 / 79-01 / 80$ & 16,7 & 35,0 \\
\hline Thoroddsen (FSF) & SSF, FSF, AB & $02 / 80-05 / 83$ & 53,3 & 28,3 \\
\hline Hermannsson I (FSF) & SSF, FSF & $05 / 83-07 / 87$ & 68,3 & 16,7 \\
\hline Palsson (SSF) & SSF, FSF, AF & $07 / 87-09 / 88$ & 65,1 & 15,9 \\
\hline Hermannsson II (FSF) & $\begin{array}{l}F S F, A B, A F, B P \\
\text { (ab 89) }\end{array}$ & $09 / 88-04 / 91$ & $\begin{array}{l}50,8 \\
\text { (ab 89: 61,9) }\end{array}$ & 28,6 \\
\hline Oddsson I (SSF) & SSF, AF & $04 / 91-04 / 95$ & 57,1 & 20,6 \\
\hline Oddsson II (SSF) & SSF, FSF & $04 / 95-05 / 99$ & 63,5 & 14,3 \\
\hline Oddsson III (SSF) & SSF, FSF & $05 / 99-05 / 03$ & 60,3 & 27,0 \\
\hline Oddsson IV (SSF) & SSF, FSF & 05/03-09/04 & 54,0 & 31,7 \\
\hline Asgrimsson (FSF) & SSF, FSF & $09 / 04-06 / 06$ & 54,0 & 31,7 \\
\hline Haarde I (SSF) & SSF, FSF & $06 / 06-05 / 07$ & 54,0 & 31,7 \\
\hline Haarde II (SSF) & SSF, S & 05/07-02/09 & 68,3 & 14,3 \\
\hline Sigurdardottir I (S) & SA, VG & 02/09-04/09 & 42,9 & 39,7 \\
\hline Sigurdardottir II (S) & $S A, V G$ & $05 / 09-04 / 13$ & 54,0 & 25,4 \\
\hline Gunnlaugsson (SSF) & SSF, FSF & $05 / 13-$ & 60,3 & 14,3 \\
\hline
\end{tabular}

Anmerkungen: SSF = Sjálfstæð̀isflokkurinn /(konservative) Unabhängigkeitspartel; FSF = Framsóknarflokkurinn/Fortschrittspartei (nichtchristliche Mitte); AF = Volkspartei (Sozialdemokraten); $A B=$ Volksallianz (Linkssozlalisten); SF = Liberale Linke (Sozialdemokraten); SA = Samfylkingin/Sozialdemokratische Allianz (Zusammenschluss von vier Mitte-Links Partelen); VG = Vinstrihreyfingin - Grænt frambod/Links-Grune Bewegung.

Quelle: Eythorsson/lahn (2009), eigene Zusammenstellung auf der Grundlage der Datenhandbucher des European Journal of Political Research sowie den Daten aus http://www.parties-andelections.eu/iceland.html (zuletzt aufgerufen 14.10.2013)

Die Finanzkrise mündete in eine isländische ,Revolution'. Bereits in der Vorweihnachtszeit 2008 kam es zu Protestkundgebungen, vor allem in der Hauptstadt Reykjavik. Die sogenannte Revolution der ,Kochtöpfe und Pfannen' (mit denen die Protestierenden ihrem Unmut lautstark Gehör verschafften) verfolgte als Ziel die Abdankung der Regierung aus Unabhängigkeitspartei sowie sozialdemokratischer Partei sowie den Rücktritt von David Oddsson als Zentralbankchef. Jedoch zögerten die Regierungsparteien, die Verantwortung für die Bankenkrise zu übernehmen. Nach dem

10 Die beiden bisherigen sozialdemokratischen Ministerpräsidenten der isländischen Geschichte, Emil Jonsson sowle Benedikt Gröndal, führten die Amtsgeschäfte jeweils nur knapp ein Jahr (19581959 bzw. 1979-1980). Dies zeugt ebenso von der relativen Schwäche der isländischen Sozialdemokratie. 
Jahreswechsel 2008/2009 eskalierte die - für isländische Verhältnisse - Gewalt ${ }^{11}$ und die sozialdemokratische Regierungspartei kündigte die Zusammenarbeit mit der Unabhängigkeitspartei auf. Mit parlamentarischer Unterstützung durch die liberale Fortschrittspartei konnte eine sozialdemokratisch-grüne Minderheitsregierung die Amtsgeschäfte übernehmen. Die neue Regierung kündigte auf dem schnellsten Wege Neuwahlen an, eine Fortführung der Verhandlungen mit dem IWF (die von der Unabhängigkeitspartei ausgesetzt worden waren), stärkere sozialpolitische Anstrengungen für die von der Finanzkrise betroffenen Menschen sowie einen raschen Mitgliedsantrag an die Europäische Union.

Die Wahl am 25. April 2009 bestätigte die bisherige Minderheitsregierung und verschaffte ihr eine knappe parlamentarische Mehrheit. Neu im Parlament vertreten ist die Partei der ,Bürgerbewegung،, die sich aus den Protestierenden der ,Kochtöpfeund Pfannen-Revolution' speist. Damit sind im isländischen Parlament auch die Parteien in der Mehrheit, die sich explizit für eine Mitgliedschaft Islands in der EU aussprechen. Das Mitgliedsverfahren wurde eröffnet, allerdings ist diese politische Initiative ebenso wie die Initiative einer von zivilgesellschaftlichen Akteuren getragenen Verfassungsreform mit der Wahl im Jahr 2013 vorerst gescheitert.

Bereits seit 2010 kündigte sich ein Regierungswechsel in den Umfragen an. Die regierende Links-Koalition verlor stetig an Rückhalt in der Bevölkerung. Hierfür kann die umstrittene Verfassungsreform als Grund genannt werden. Die Reform sollte das Wahlrecht reformieren, von dem die ländlichen Bevölkerungsteile stark bevorzugt werden. Zudem wollte die Verfassungsreform die Lizenzvergabe der Fischereiindustrie neu regeln bzw. ,vergesellschaften'. Auch dies stieß vor allem in den ländlichen Regionen auf Widerstand. Als zudem die Regierung bei zwei Referenden zur Lösung der Icesave-Krise unterlag, schien die Autorität der Koalition gebrochen - und fast parallel stiegen die Umfragewerte für die Unabhängigkeitspartei (und die Fortschrittspartei) stark an. Mit der Wahl im April 2013 ergab sich dann eine deutliche Mehrheit für die ,alten“ Parteien der isländischen Demokratie. Mit über 60 Prozent der Sitze ist die Mehrheit deutlich (vgl. Tabelle 9). Und mit der Wahl von 2013 scheint auch die Funktionsweise der ,alten" isländischen Demokratie restauriert worden zu sein: Die neue isländische Regierung brach die Beitrittsverhandlungen mit der EU ab und legte die Verfassungsreform auf Eis. Ob jedoch die alten, eher nepotistischen Beziehungen zwischen den jetzigen Regierungsparteien und der isländischen Wirtschaft und Fischereiindustrie nach der Finanzkrise und den damit einhergehenden öffentliche Protesten wiederhergestellt werden kann, erscheint fraglich (Jochem 2013c).

11 Die ,Gewaltanwendungen' hielten sich in engen Grenzen. Zwar wurden teilweise ,Wurfgeschosse von den Protestierenden auf das isländische Parlament geworfen. Allerdings wird als einziger ,Personenschaden' ein Schneeballwurf auf den Ministerpräsident Haarde in den Chroniken verzeichnet. Die Polizei setzte zwar Tränengas gegen die Demonstranten ein, blieb insgesamt allerdings betont passiv. 


\subsection{Oberste Gerichtsbarkeit und Rechtssystem}

In allen nordischen Staaten wird die Unabhängigkeit der Judikative verfassungsmäßig abgesichert. Letztlich unterscheiden sich die Rechtssysteme der nordischen Länder in einigen Details. Grundlegend ist jedoch ein Aufbau unterschiedlicher Instanzen und vor allem in Schweden und Finnland eine starke Ausrichtung der Rechtstradition auf Deutschland. Gleichwohl ist zu betonen, dass im Norden die Obersten Gerichtshöfe keineswegs ein politisches Gewicht einnehmen, wie dies in Deutschland der Fall ist. International vergleichende Studien zur Gewichtung des politischen Einflusses der Obersten Gerichtshöfe attestieren den nordischen Gerichtshöfen nur einen geringen Einfluss. Dies bezieht sich nicht nur auf die Routine des gewöhnlichen Policy-Makings sondern auch auf die Kompetenzen der obersten Gerichtshöfe im Prozess der Verfassungsauslegung und -kontrolle (Lijphart 1999: 216-230).

Entscheidend für die nordischen Rechtssysteme sind jedoch die Europäisierungstendenzen der jüngsten Vergangenheit. Trotz unterschiedlicher Integrationsschritte der nordischen Länder wirkt die Europäisierung des Nordens in der gesamten Region. Die europäische Rechtsentwicklung wird dabei im Norden rasch und ohne nennenswerte Veränderungen in nationales Recht umgesetzt.

\subsection{Zentralbanken}

Eine weitere wichtige Institution im politischen Entscheidungsprozess stellen die nationalen Zentralbanken dar. Wie im Bereich der Obersten Gerichtshöfe kann hier für einige Länder des Nordens eine Europäisierung attestiert werden. Während historisch betrachtet die Zentralbanken bis in die 1980er-Jahre eher von den Vorgaben der jeweiligen Regierungen abhängig waren, wurde seither die Autonomie und Unabhängigkeit schrittweise ausgebaut. Mit der zunehmenden europäischen Integration des Nordens sowie dem finnischen Beitritt zum Euroraum (als auch der faktischen Ankoppelung der dänischen Krone an die Vorgaben der EZB) ist dort eine zunehmende Unabhängigkeit der Zentralbank gemäß den europäischen Vorgaben institutionalisiert - mit allen Konsequenzen für die Freiheitsgrade der Politikgestaltung seitens der Regierungen, wie in Kapitel 4 erörtert wird. Auf der anderen Seite der Skala rangiert die faktische Abhängigkeit der isländischen Zentralbank von der Regierung (bzw. der Unabhängigkeitspartei). Erst mit der finanz-, geld- und währungspolitischen Kernschmelze wurde die Stellung der isländischen Zentralbank von der rot-grünen Koalition gestärkt - es wurde zudem festgeschrieben, dass der zukünftige isländische Zentralbankchef eine fachspezifische Ausbildung genossen haben muss. Hiermit soll eine nepotistische Verflechtung zwischen isländischer Politik, dem Bankenwesen sowie der Zentralbank für die Zukunft verhindert werden. Zudem wurde als erster Zentralbankchef Islands nach David Oddsson - wenn auch nur für sieben Monate - der Norweger Svein Harald Øygard berufen, dies sollte die intimen Verbindungen zwischen 
isländischer Politik und isländischem Bankenwesen in der Hochphase der isländischen Finanzkrise aufbrechen.

\subsection{Administrativer Aufbau}

Die Behörden in Skandinavien sind prinzipiell dreifach strukturiert. Auf zentralstaatlicher Ebene befinden sich die (kleinen) Ministerien und (ebenfalls kleine) zentralstaatliche Administrationen. Auf regionaler und vor allem lokaler Ebene sind die Verwaltungsbehörden weiter differenziert. Der Schwerpunkt der Verwaltung im Norden ist dabei auf lokaler Ebene angesiedelt, die regionalen als auch lokalen Gebietskörperschaften besitzen gewisse Besteuerungskompetenzen. Daher ist es nicht verwunderlich, dass in den zentralisierten Staaten des Nordens zwar der Großteil des gesamten Steueraufkommens auf den Zentralstaat entfällt, dieser Anteil jedoch deutlich niedriger ausfällt als in anderen zentralisierten Demokratien (Lijphart 1999: 191-195).

Dieser skandinavische Verwaltungsaufbau trägt mit dazu bei, dass zum einen die Lebensbedingungen im Norden von Region zu Region variieren sowie zum anderen die Verbindungen der Menschen zu den lokalen Verwaltungseinheiten und politischen Gremien stark ausgeprägt ist. Die regionalen und lokalen Gebietskörperschaften können zwar nicht die zentralstaatlich festgelegten Bedingungen der Politik (und insbesondere der Sozialpolitik) konterkarieren, aber sie können Freiräume zur eigenen Politikgestaltung nutzen und gegenüber der regionalen und lokalen Wahlbevölkerung unmittelbar vertreten.

So ist es zum Beispiel zu erklären, dass im Großraum Stockholm - einer Hochburg der bürgerlichen Parteien in Schweden - die Steuern tendenziell niedriger aber auch der Anteil des privatisierten Gesundheitsbereichs höher ausfällt als im Norden des Landes, wo die linken Parteien immer noch die politischen Geschicke dominieren. Ferner ermöglicht die in Grenzen gegebene Besteuerungskompetenz auch eine unmittelbare Verbindung dieser Politik mit den Prozessen der lokalen Demokratie. Die Bevölkerung vor Ort kann sehr unmittelbar über Steuerpolitiken mit entscheiden. Einer solchen Politik wird mitunter eine höhere demokratische Akzeptanz attestiert.

Die Verwaltungsstruktur in Island ist stärker zentralisiert als in den anderen nordischen Demokratien. Unterhalb der zentralstaatlichen Ebene sind lediglich kommunale Verwaltungseinheiten eingerichtet, eine mittlere Ebene fehlt (auch wegen der geringen Größe der Inselrepublik). Aufgrund der zum Teil sehr kleinen Kommunen in Island übernimmt der Zentralstaat die meisten Verwaltungsaufgaben.

\subsection{Politikverflechtung mit der EU}

Die europäische Integration des Nordens erfolgt in unterschiedlichem Tempo und mit unterschiedlichen Strategien. Die kleinen Länder des Nordens waren stets darauf 
ausgerichtet, ihre eigenständigen - und mitunter moralisch ambitionierten - Politikziele zu verfolgen. Mit dem Voranschreiten der Integration in Europa kam es zu vermehrten Integrationsprozessen auch im Norden, mit den daraus resultierenden Politikverflechtungen zwischen den souveränen Territorialstaaten und vor allem den Institutionen der Europäischen Union. In Tabelle 10 wird aufgezeigt, welch unterschiedliche Einbettung die nordischen Länder in außen- und sicherheitspolitische Organe erfahren.

Tab. 10: Muster außen- und sicherheitspolitischer Verflechtungen im Norden

\begin{tabular}{l|ll|llll}
\hline & NATO & & EU & & \\
\hline & Mitglled & PfP') & Mitglied & Eurozone & EFTA/EWR ${ }^{23}$ & Schengen \\
Danemark & $\mathrm{X}$ & & $\mathrm{X}$ & & & $\mathrm{X}$ \\
Finnland & & $\mathrm{X}$ & $\mathrm{X}$ & $\mathrm{X}$ & & $\mathrm{X}$ \\
Island & $\mathrm{X}$ & & & & $\mathrm{X}$ & $\mathrm{X}$ \\
Norwegen & $\mathrm{X}$ & & & $\mathrm{X}$ & $\mathrm{X}$ \\
Schweden & & $\mathrm{X}$ & $\mathrm{X}$ & & & $\mathrm{X}$ \\
\hline
\end{tabular}

Anmerkungen: ${ }^{2}$ Partnership for Peace, ${ }^{2}$ EWR = Europäischer Wirtschaftsraum

Quelle: eigene Zusammenstellung; Stand Herbst 2013 (vgl. Jochem 2012)

Insbesondere die Institutionen der Europäischen Union üben einen unterschiedlichen Einfluss auf die politischen Systeme des Nordens aus. Während drei von fünf Ländern des Nordens Mitglied in der EU sind, partizipieren alle Länder am sogenannten ,Schengenabkommen'. Während einzig in Finnland der Euro eingefihrt wurde und Dänemark sich unbedingt mit der dänischen Krone an den Euro angekoppelt hat, sind die politischen Freiräume in Schweden größer; noch größer sind die politischen Freiräume in der Währungspolitik in Norwegen und Island (vgl. Kapitel 4 für Details). Insofern kann für den Norden attestiert werden, dass die territorialstaatlichen formalen Institutionen in unterschiedlicher Weise von transnationalen Prozessen der Politikgestaltung beeinflusst werden. Bevor auf die Funktionsweise detailliert eingegangen werden kann, sollen jedoch die informellen Institutionen der nordischen Politik kurz erläutert werden.

\section{Informelle Routinen demokratischer Politik}

Die nordischen Demokratien erfüllen hohe Anforderungen an eine autonome und verlässliche Rechtsstaatlichkeit sowie an eine demokratische Transparenz; zudem ist ökonomische oder politische Korruption nahezu inexistent, und die Akteure demokratischer Politik profitieren von einem hohen Maß gesellschaftlichen Vertrauens (Ervastl 
et al. 2008; Kangas/Palme 2005, Jochem 2012). ${ }^{12}$ Einige staatliche Institutionen im Norden schreiben politische Systeme vor, die in zentralstaatlicher Verfassung dem Mehrheitsprinzip - also dem Prinzip des parteipolitischen Wettbewerbs - durchaus einen Vorrang gewähren. In den Worten von Arend Lijphart (1999) wären die Mehrzahl der formalen Institutionen in den politischen Systemen des Nordens eher einem Typus der tendenziellen Mehrheitsdemokratie zuzuordnen (Arter 2006; Esaiasson/Heidar 2000). Gleichwohl erscheinen uns die nordischen Demokratien als Vorbilder eines konsensualen Regierens, eines pragmatischen Interessenausgleichs sowie eines unaufgeregten Beilegens politischer Konflikte. Es wird in diesem Kapitel zu zeigen sein, dass dieses Bild konsensualer Demokratien auf informelle politische Routinen zurückzuführen ist - diese informellen Routinen schwächten sich jedoch in den vergangenen Jahrzehnten tendenziell ab.

Hinsichtlich der demokratischen Qualität repräsentieren die nordischen Länder eine eindeutig abgrenzbare Spitzengruppe. Verschiedene Messungen demokratischer Qualität bezeugen den nordischen Ländern ihre jeweiligen Spitzenpositionen im internationalen Vergleich (vgl. Tabelle 11). Allgemeine (und grobe) Einstufungen von Freedom-House bezeugen eine allgemeine freiheitliche Ordnung. Differenziertere Messung vom Economist, der Bertelsmann Stiftung oder des Democracy-Barometers bekräftigen die internationale Spitzenstellung, ermöglichen aber länderspezifische Differenzierungen. Während der Economist und der Democracy-Barometer zum Beispiel Island in die internationale Spitzengruppe mit einrechnen, sprechen die Messungen der Bertelsmann Stiftung eher für vorsichtigere Einstufungen. Diese vorsichtigere Einstufung der isländischen Demokratie wird unterstützt durch international vorgenommene Einschätzungen, inwieweit Korruption ein Problem für demokratische Prozesse darstellt.

Informelle Routinen demokratischer Politik sind schwerlich auf präzise Begriffe und Konzepte zu bringen. In Skandinavien haben sich spätestens seit den 1930erJahren Routinen und politische Verhaltensweisen herausgebildet, die grob vereinfachend auf die begrifflichen Nenner des Vertrauens, des Pragmatismus sowie des Korporatismus zu bringen sind. Diese Routinen sind keineswegs nur kulturell begründet. Vielmehr sind sie eingebettet in einen Begründungszusammenhang aus erstens kulturellen (oder religiösen) Normen und Wertvorstellungen sowie zweitens historisch sich entwickelnden Effekten, die von den formalisierten Institutionen des politischen Systems wieder zurück auf die Gesellschaft ausstrahlen. Letztlich basiert das Zusammenspiel zwischen formalen politischen Institutionen und informellen Regeln des politischen Wettbewerbs auf einer spezifischen Machtverteilung in der Gesellschaft, die im historischen Kontext allerdings variabel ist (Esping-Andersen 1985; Ervasti et al. 2008).

12 Es ist zu betonen, dass die isländische Demokratie von diesem nordischen Muster eindeutig abweicht. Vgl. hierzu die Ausführungen am Ende des Unterkapitels. 
Tab. 11: Nordische Demokratiequalităten

\begin{tabular}{|c|c|c|c|c|c|c|}
\hline & $\begin{array}{l}\text { SGI } \\
\text { Bertelsma }\end{array}$ & ann-Stiftung & Freedom- & Economist & Democracy & Korruption \\
\hline & $\begin{array}{l}\text { Status } \\
\text { Index }\end{array}$ & $\begin{array}{l}\text { Management } \\
\text { Index }\end{array}$ & House Index & $\begin{array}{l}\text { Demokratie } \\
\text { Messung }\end{array}$ & Barometer & \\
\hline & $\begin{array}{l}\text { Stand } 201 \\
\text { (Rangplüt }\end{array}$ & ze in Klammern) & Stand 2012 & $\begin{array}{l}\text { Stand } 2012 \\
\text { (Rangplatze } \\
\text { in Klammern) }\end{array}$ & $\begin{array}{l}\text { Stand } 2005 \\
\text { (Rangplatze) }\end{array}$ & $\begin{array}{l}\text { Stand } 2012 \\
\text { (Rangplatze } \\
\text { In Klammern) }\end{array}$ \\
\hline Dänemark & $8,34(5)$ & $7,90(3)$ & Free & $9,52(4)$ & 1 & $90(1)$ \\
\hline Finnland & $8,52(3)$ & $7,79(4)$ & Free & $9,06(9)$ & 2 & $90(1)$ \\
\hline Island & $7,65(10)$ & $7,23(8)$ & Free & $9,65(3)$ & 4 & $82(11)$ \\
\hline Norwegen & $8,64(2)$ & $8,20(2)$ & Free & 9,93 (1) & 6 & $85(7)$ \\
\hline Sentedin & $8,65(1)$ & $8,29(1)$ & Free & $9,73(2)$ & 5 & $88(4)$ \\
\hline $\begin{array}{l}{ }^{n} \mathrm{~N}^{\mathrm{N}} \text { der } \\
\text { Studien }\end{array}$ & 31 & 31 & $\begin{array}{l}195 \text { (und } \\
14 \text { Tenitorien) }\end{array}$ & 167 & 30 & 174 \\
\hline
\end{tabular}

Quelle:Sustainable Governance Indicators 2011 der Bertelsmann Stiftung: http://www.sglnetwork.org/index.php?page= download_2011; Freedom in the World 2013: Democratic Breakthroughs in the Balance: http://www.freedomhouse.org/sites/default/files/FIW\%202013\%20 Charts\%20and\%20Graphs\%20for\%20Web_0.pdfThe Economist Intelligence Unit Limited 2013: https://portoncv.gov.cv/dhub/porton.por_global.open_file?p_doc_Id=1034. Democracy Barometer, Rangliste der Demokratlequalităt: http://www.democracybarometer.org/ranking_de.html. Corruption Perception Index, Transparency International: http://cpi.transparency.org/cpi2012/ results/ (zuletzt aufgerufen 14.10.2013)

Die nordischen Länder belegen bei empirischen Untersuchungen zum gesellschaftlichen und politischen Vertrauen stets obere Rangplätze. Diese empirischen Ergebnisse lösen mitunter Irritationen aus, da erwartet wird, der umfassende nordische Sozialstaat schließe gesellschaftliches Engagement, Freiwilligkeit oder solidarische Aktivitäten jenseits staatlicher Obhut im weiteren Sinne aus (,Crowding-out-These'). Wie Bo Rothstein aber in mehreren Publikation ausführt, sind es just die spezifischen Formen nordischer Sozialstaatlichkeit (Universalismus, Egalitarismus, rechtsstaatliche Neutralität), die dafür sorgen, dass eine umfassend ausgebaute Sozialpolittk eher gesellschaftliches und politisches Vertrauen stärkt als schwächt (Rothstein 2010, 2012).

Eine international vergleichende Messung unterschiedlicher Aspekte des gesellschaftlichen Vertrauens belegt die nordischen Spitzenpositionen (vgl. Tabelle 12). Dänemark, Norwegen, Finnland und Schweden führen in dieser Studie, die sich auf Daten des European Social Surveys bezieht, die Rangliste des generalisierten Vertrauens deutlich an. Aber auch in anderen Aspekten des Vertrauens, wie der Mitgliedschaft in freiwilligen Organisationen, freiwilliges Engagement im allgemeinen Sinne oder gar die Spendentätigkeit nordischer Bürger führen nordische Länder die europäische Rangliste an. Lediglich für Finnland wird in den genannten Teilbereichen eine eher durchschnittliche Rangfolge dokumentiert. Leider werden Daten für Island nicht 
aufgeführt. Neuere Studien zeigen jedoch, dass zu Beginn des neuen Jahrhunderts die Werte für gesellschaftliches Vertrauen auch in Island hoch waren, durchaus vergleichbar mit dem schwedischen Niveau. Und diese Studien zeigen zudem den bemerkenswerten Befund, dass trotz rapide sinkenden Vertrauens der isländischen Bevölkerung in politische Gremien und Akteure das zwischenmenschliche Vertrauen und das freiwillige Engagement tendenziell während der Finanzkrise eher zugenommen haben (Growiec/Vilhelmsdóttir/Cairns 2012).

Tab. 12: Sozialkapital und freiwilliges Engagement im internationalen Vergleich

\begin{tabular}{|c|c|c|c|c|c|c|c|}
\hline \multicolumn{2}{|c|}{$\begin{array}{l}\text { Generalisiertes } \\
\text { Vertrauen }\end{array}$} & \multicolumn{2}{|c|}{$\begin{array}{l}\text { Mitgliedschaft in } \\
\text { frelwilligen Organi- } \\
\text { sationen }\end{array}$} & \multicolumn{2}{|l|}{$\begin{array}{l}\text { Freiwilliges } \\
\text { Engagement }\end{array}$} & \multicolumn{2}{|c|}{$\begin{array}{l}\text { Spenden und Geld- } \\
\text { leistungen fur freiwil- } \\
\text { lige Organisationen }\end{array}$} \\
\hline Land & Wert & Land & Wert & Land & Wert & Land & Wert \\
\hline Dănemark & 6,81 & Dănemark & 92 & Norwegen & 37 & Niederlande & 44 \\
\hline Norwegen & 6,53 & Schweden & 90 & Schweden & 35 & Schweden & 44 \\
\hline Finnland & 6,34 & Niederlande & 84 & Niederlande & 29 & Norwegen & 41 \\
\hline Schweden & 6,25 & Norwegen & 84 & Dănemark & 28 & UK & 40 \\
\hline Irland & 5,80 & Luxemburg & 78 & Deutschland & 26 & Österreich & 38 \\
\hline Schweiz & 5,72 & Finnland & 76 & Belgien & 23 & Deutschland & 34 \\
\hline Niederlande & 5,72 & Österreich & 75 & UK & 23 & Dänemark & 34 \\
\hline UK & 5,34 & Belgien & 71 & Frankreich & 19 & Irland & 32 \\
\hline Osterreich & 5,31 & Deutschland & 71 & Irland & 16 & Belgien & 26 \\
\hline Deutschland & 5,10 & UK & 70 & Luxemburg & 15 & Frankreich & 23 \\
\hline Luxemburg & 5,06 & Irland & 68 & Osterreich & 14 & Finnland & 19 \\
\hline Belgien & 4,96 & Frankreich & 50 & Finnland & 12 & Luxemburg & 19 \\
\hline Spanien & 4,84 & Spanien & 36 & Spanien & 7 & Portugal & 16 \\
\hline Frankreich & 4,81 & Italien & 35 & Griechenland & 6 & Spanien & 15 \\
\hline Portugal & 4,43 & Portugal & 29 & Portugal & 6 & Itallen & 12 \\
\hline Itallen & 4,40 & Griechenland & 25 & Italien & 5 & Griechenland & 9 \\
\hline Griechenland & 3,45 & & & & & & \\
\hline
\end{tabular}

Anmerkungen: Die Analysen von Friedberg und Kangas beruhen auf dem European Social Survey (ESS) aus dem Jahr 2002. Die Variable ,Generalisiertes Vertrauen' ist ein Durchschnittsindikator aus drei Fragen, die im ESS zur Auswahl standen und die Aspekte des Vertrauens, der Hilfsbereitschaft sowle der Fairness umfassen. Der Indikator erstreckt sich von 0 bis 10, wobei hohe Werte ein hohes $\mathrm{Maß}$ an generalisiertem Vertrauen ausdrucken. Die anderen Indikatoren sind Prozentangaben. Im EES wurde gefragt, ob die Befragten innerhalb der letzten 12 Monate Mitglied in einer freiwilligen Organisation waren, ob sie sich in den Organisation en freiwillig betătigt haben, oder ob sie diesen Organisationen Geld gespendet haben.

Quelle: Fridberg/Kangas (2008: 70, 71, 78), vgl. Jochem (2012: 115)

Die nordischen Demokratien sind auf vielschichtige Weise in dieses Fundament eines umfassend ausgeprägten gesellschaftlichen Vertrauens eingebettet. Zum einen bewirkt das Vertrauen eine grundsätzliche Offenheit gegenüber politischen Akteuren. Ebenso beinhaltet dieses Vertrauen auch tendenziell - wenngleich nicht universell - 
eine Offenheit gegenüber ,Fremden ${ }^{6}{ }^{13}$ Zum anderen impliziert das hohe gesellschaftliche Vertrauen eine besondere Legitimationsbasis für politische Akteure. Eine ,Parteien-" oder ,Politikverdrossenheit' ist zwar in Ansätzen auch im Norden zu beobachten, allerdings ist das Ausmaß dieser Erosionstendenzen (noch) eher gering ausgeprägt, insbesondere wenn man die nordische Situation mit der Situation in Kontinental- und vor allem Südeuropa vergleicht.

Das gesellschaftliche und politische Vertrauen ermöglicht in der Konsequenz eine ausgeprägte Form des politischen Pragmatismus. Seit den 1930er-Jahren zeichneten sich die politischen Akteure im Norden dadurch aus, dass sie pragmatische Koalitionen eingingen, die über ideologische bzw. programmatische Lagergrenzen hinweg Sachlösungen anbahnten. Diese Kompromisse waren keineswegs konfliktfrei. Im Gegenteil implizierten sie nicht nur zwischen den ungewohnten Koalitionspartnern intensive Konflikte, sondern vor allem auch innerhalb der jeweiligen Lager. Diese frühen Formen des lagerübergreifenden Pragmatismus in den 1930er-Jahren werden in der Literatur gerne als ,Kuhhandel' zwischen sozialdemokratischen Parteien einerseits und agrarischen Zentrumsparteien andererseits beschrieben (Esping-Andersen 1985). Seit den 1980er-Jahren gingen jedoch Formen pragmatischer Kooperation über politische Lagergrenzen in fast ganz Skandinavien eher zurück.

Die finnische Politik allerdings zeichnet sich bis auf den heutigen Tag durch eine mitunter atemberaubend anmutende Pragmatik aus: "Governments have proceeded on an ,anything goes' basis, coalitions have involved the cohabitation of strange bedfellows" (Arter 2008b: 235). In Finnlands Großen Koalitionen kamen parteipolitische Akteure zusammen, die nur schwerlich aus einer kontinentaleuropäischen Perspektive in dieser breiten Konstellation vorstellbar wären. Es ist zu betonen, dass dieser Pragmatismus zwar auf dem Fundament des gesellschaftlichen Vertrauens fußt, dass dieser Pragmatismus aber auch durch formale Institutionen geprägt wurde (siehe die Ausflihrungen oben).

Die Fundamente des politischen Pragmatismus sind in jüngster Zeit brüchig geworden. Wichtige parteipolitische Akteure folgen nicht mehr unbedingt den pragmatischen Routinen politischer Konsenssuche. Am Beispiel von Schweden wird deutlich, wie sich die bürgerlichen Parteien zum einen programmatisch annäherten und zum anderen die - dominierende - Konservative Partei (M) explizit einen Lagerwahlkampf forciert. Die gegenwärtige Notwendigkeit zu pragmatischen Verhandlungen über die politischen Lagergrenzen hinaus wird einzig durch fehlende parlamentarische Mehrheiten erzwungen. In den anderen Ländern hingegen sind diese Formen des Pragmatismus immer noch zu beobachten (wie in Finnland oder Norwegen bis zur Wahl 2013)

13 Hier ist zu betonen, dass diese tendenzielle Offenheit gegenüber Fremden vereinbar $z \mathfrak{u}$ sein scheint mit durchaus sehr erfolgreich im politischen Wettbewerb auftretenden rechtspopulistischen Parteien. Vgl, hierzu die Publikationen von Jens Rydgren (2009, 2010, 2011). 
bzw. versuchen politische Akteure einen solchen Pragmatismus wieder neu zu beleben (Dänemark nach 2011).

Mit dem Begriff des Korporatismus werden politische Routinen umschrieben, die eine systematische Integration von Interessenverbänden in den Prozess der Politikgestaltung und Politikimplementierung ebenso umfassen wie eine gewisse Selbststeuerungskompetenz der Interessenverbände in bestimmten Politikfeldern (,Private Interest Government'). Beide Aspekte korporatistischer Interessenvermittlung sind im Norden vergleichsweise stark ausgeprägt.

Empirische Messungen der korporatistischen Interessenvermittlung und Politikkonzertierung existieren - sie sind allerdings aus vielen Gründen umstritten. Gleichwohl rangieren die nordischen Länder bei diesen metrischen Schätzungen meist in der Spitzenposition. In der klassischen Studie von Siaroff (1999) werden zum Beispiel Norwegen, Schweden und Dänemark einem eher starken Korporatismus zugeordnet, Finnland hingegen einem moderaten Korporatismus und Island schließlich ist von der Analyse ausgeschlossen, da zu diesem Land zu wenige Studien vorliegen.

In institutionalistischer Hinsicht stellen sowohl tripartistisch besetzte Verwaltungsleitungen als auch dauerhaft auf Verbandsbeteiligung ausgerichtete Kommissionen der nordischen Parlamente wichtige korporatistische Anreize zur Öffnung des Entscheidungsprozesses hin zu gesellschaftlichen Interessen dar. In beiden Hinsichten berichten empirische Studien von einer rückläufigen Integration der Verbandsinteressen im politischen Entscheidungs- und Implementationsprozess (Öberg et al. 2011). Statt einer systematischen Integration der von der Entscheidung betroffenen Verbände werde tendenziell stärker auf sogenannte ,Experten' aus dem Wissenschaftsbereich rekurriert.

Jenseits institutionalisierter Routinen wird in kultureller Hinsicht eine Sozialpartnerschaft zwischen den wichtigsten Verbänden auf den nordischen Arbeitsmärkten attestiert. Allerdings scheint auch diese informelle Regel in vielen nordischen Ländern brüchig geworden zu sein. Einerseits erodiert die Selbststeuerungskraft der Verbände in vielen Bereichen, nicht zuletzt in so zentralen Bereichen wie der Lohnpolitik oder bei der Ausgestaltung der Bildungs- und Arbeitsmarktpolitik. Andererseits kämpfen auch im Norden die Verbände mit einer rückläufigen Organisationsstärke, was die Bereitschaft der Verbandseliten schmälert, sich auf für die Mitgliederinteressen nicht unbedingt unumschränkt vorteilhafte Paketverhandlungen einzulassen. Diese genannten Entwicklungen legen es nahe, dass in vielen Aspekten korporatistischer Konzertierung im Norden die informellen Praktiken des Interessenausgleichs sowie der verbandlichen Steuerung zwar noch existieren, sie allerdings in ihrer Intensität rückläufig bzw. in ihrer Verpflichtungsfähigkeit prekär sind.

Die genannten informellen Routinen einer konsensualen demokratischen Interessenvermittlung weichen in Island vom Muster der anderen nordischen Länder ab. Bereits vor der Finanzkrise erschien die Demokratie in Island zwar aus formaler Hinsicht von hoher Qualität zu sein, allerdings führte die Dominanz der beiden großen bürgerlichen Parteien (Unabhängigkeitspartei sowie Fortschrittspartei) zu ,nicht- 
nordischen' Routinen des Nepotismus, einer für nordische Verhältnisse hohen Korruption sowie einer eingeschränkten demokratischen Transparenz. So intervenierte zum Beispiel die bürgerliche Koalition nicht nur in die Rechtsprechung des Obersten Gerichtshofs (der in seiner personalen Besetzung weitgehend von der Unabhängig. keitspartei bestimmt wurde), auch die Vergaberoutinen gewisser politischer Ämter nicht zuletzt des Präsidentenamts der isländischen Zentralbank - und die Vergabe von Ämtern in den frisch privatisierten Geschäftsbanken sind eher Beispiele eines ausgeprägten isländischen Nepotismus (wenn diese Verfahren aus nordischer Perspektive und nicht aus südeuropäischer Perspektive bewertet werden). Wie intensiv sich diese geschlossenen Zirkel zwischen Wirtschaft und Politik auch mit den entscheidenden Akteuren der aufstrebenden Finanzwirtschaft verbündeten, wurde erst nach Ausbruch der Finanzkrise in Island deutlich und dokumentiert - unter anderem in einem voluminösen und detaillierten Bericht des isländischen Parlaments (Gylfason 2012; Jochem 2013c).

Formale Institutionen und informelle Routinen des demokratischen Prozesses haben sich lange Zeit im Norden ergänzt und in der Summe eher konsensuale Verhandlungsdemokratien befördert. Allerdings zeigen die jüngsten Entwicklungen, wie prekär vor allem die informellen Routinen im Norden verankert sind. Welche Konsequenzen diese veränderten Wechselbeziehungen zwischen formalen und informellen Routinen der nordischen Demokratien auf die Politikgestaltung haben, kann am Beispiel des Krisenmanagements in der globalen Finanzkrise gezeigt werden.

\section{Formales und informelles Regieren in der Finanzkrise}

Die ,Great Recession' traf die nordischen Länder mit ihren kleinen und offenen Marktwirtschaften unvermittelt und stark. Während in Island das dortige Finanzsystem im weiteren Verlauf der Krise eine ,Kernschmelze' durchlief - mit gravierenden politischen Auswirkungen -, konnte hingegen in Norwegen, Schweden und Finnland die Krise rasch durchschritten werden. In Dänemark hingegen sehen sich die politschen Akteure mit ökonomisch-strukturellen Verwerfungen konfrontiert, die auf politische Fehlentscheidungen der vergangenen Jahre zurückzuführen sind und sich gegen Ende des Jahres 2013 noch nicht aufgelöst haben.

Für Norwegen, Schweden und Finnland äußerte sich die Finanzkrise zuförderst als Krise der Exportwirtschaft (Dølvik/Goul Andersen/Vartiainen 2011, 2012). Mit dem ökonomischen Abschwung nach 2007 gerieten die exportorientierten Sektoren dieser Länder in große Probleme; und die politischen Akteure konnten sowohl durch ,Selbststeuerung (wie in Schweden) aber auch mithilfe staatlicher Politiken flexible Lösungen zur Vermeidung lang anhaltender hoher Arbeitslosigkeit finden (Svalund et al. 2013). 
In Dänemark ist die Krise seit 2007 nur zum Teil auf internationale Quellen zurückzuführen (Goul Andersen 2011). Durch eine prozyklische Wirtschafts- und Finanzpolitik und politische Weichenstellungen bei der Regulierung des Finanz- und Wirtschaftssystems vor 2007 manövrierte sich die dänische Ökonomie in ihre schwerste Wirtschaftskrise in Friedenszeiten (Goul Andersen 2013) - und bis zum Ende des Jahres 2013 sind noch keine deutlichen Signale einer raschen Wirtschaftsbelebung in Dänemark zu vernehmen.

Das isländische Beispiel hingegen zeugt von einer fundamentalen Krise des Finanz- und Wirtschaftssystems in der westlichen Welt. Ohne Zweifel waren wichtige Krisenfaktoren nicht allein der isländischen Politik geschuldet. Aber ebenso kann ohne Zweifel auch die These vertreten werden, dass sich die isländische Politik seit den 1990er-Jahren nicht nur durch nepotistische Ämterkumulation und eine Aushöhlung der Rechtsstaatlichkeit auszeichnete, sondern auch im Finanzbereich wichtige Weichenstellungen für eine tiefe Krise in Reykjavik gestellt wurden (Gylfason 2012; Jochem 2013c).

Die nordischen Varianten des Kapitalismus (Mjøset 2011) fußen auf dezidierten Verhandlungslösungen zwischen politisch-demokratischen und politisch-wirtschaftlichen Akteuren. Mit der Finanzkrise nach 2007 gerieten diese Verhandlungsformen, das Zusammenspiel formaler und informeller Institutionen im Norden zumindest in einen Stresstest (Svalund et al. 2013; Dølvik/Goul Andersen/Vartiainen 2012). Inwiefern diese Institutionen diesen Stresstest aus welchen Gründen bestanden, wird im Folgenden erörtert.

\subsection{Partizipation}

Krisen können Fenster öffnen für eine Stärkung der Bürgerbeteiligung, mitunter gar für ,Revolutionen‘. Das isländische Beispiel zeigt, wie im Kielwasser der Finanzkrise nicht nur die defekte Funktionsweise der isländischen Demokratie offenbart wurde, sondern mit der Finanzkrise auch das gesellschaftliche Engagement unmittelbar anstieg. In der Finanzkrise wehrte sich ein großer Teil der isländischen Bevölkerung gegen die parteipolitische Elite im Allgemeinen sowie gegen die Machtstellung der konservativen Unabhängigkeitspartei im Besonderen. Die untypischen Formen der politischen Mobilisierung führten zum Rücktritt der Regierung, vorgezogenen Neuwahlen, dem Entstehen neuer Parteien sowie politischen Zäsuren von historischer Bedeutung (Beitritt zur EU, deliberative Verfassungsreform), die allerdings nach nur einer Legislaturperiode mit der Wahl im April 2013 wieder rückgängig gemacht wurden (Jochem 2013c). Island ist insofern beispielhaft für die direktdemokratische Ausweitung der Partizipation in der Krise.

Eine Finanzkrise kann aber auch zur Stärkung des parteipolitischen Wettbewerbs sowie einer Stärkung von (als erfolgreich eingeschätzten) Regierungen führen. In Norwegen sah sich eine Mitte-Links-Koalition, in Schweden eine rein bürgerliche 
Vierparteienkoalition mit den Herausforderungen des Krisenmanagements konfrontiert. Während die norwegische Regierung rasch relativ große Krisenpakete auflegte (Dølvik/Goul Andersen/Vartiainen 2011), implementierte die bürgerliche Koalition in Schweden nur zögerlich eher überschaubare kontrazyklische Maßnahmen. Trotz des unterschiedlichen Engagements zu Beginn der Krise konnten beide Koalitionen (und vor allem die stärksten Parteien in den jeweiligen Koalitionen, also die norwegische Sozialdemokratie bzw. die schwedische Konservative Partei) vom jeweiligen Krisenmanagement an der Wahlurne profitieren. Während 2007/2008 die Umfragewerte in Schweden und Norwegen eine Abwahl der bestehenden Koalitionen nahe legten, konnten im Verlauf der Krise die jeweiligen Regierungen in der Gunst der Wähler wieder zulegen. In Norwegen verteidigte die Mitte-Links-Koalition 2009 ihre parlamentarische Mehrheit (wenn auch knapp), in Schweden gewann die bürgerliche Koalition zwar die Wahl im Jahr 2010, verlor jedoch ihre parlamentarische Mehrheit, da eine rechtspopulistische Partei (Schwedendemokraten) in den Reichstag einziehen konnte.

In Dänemark und Finnland führte die Finanzkrise bzw. das Krisenmanagement zur Abwahl von Regierungen (2011). Insbesondere in Finnland kam es im Wahlkampf zu einer Mobilisierung gegen die EU und die europäischen Krisenpakete für südeuropäische Länder. Diese kritische Stimmung resultierte in einem beachtlichen Wahlerfolg für die rechtspopulistischen Wahren Finnen, die ihren Wähleranteil fast verfünffachen konnten und nun mit 19 Prozent der Wählerstimmen die drittstärkste Fraktion im finnischen Parlament (Eduskunta) bilden (Arter 2013).

Andere Wege der Bürgerbeteiligung ereigneten sich in öffentlichen Debatten sowie einer zunehmenden Mobilisierung nordischer Verbände in der Krise. Die öffentlichen Debatten im Norden sind nicht nur lebhaft, sie verzahnen zudem Akteure aus der Wissenschaft mit Akteuren aus der Politik und insgesamt verschieben sie sich immer stärker auf digitalisierte Medien. So forcierte eine über internetbasierte soziale Medien verlaufende Debatte in Island die Verfassungsreform. In den anderen nordischen Ländern mobilisierten Verbände alternative Vorschläge zur Krisenpolitik. Allerdings waren diese alternativen Vorschläge nur zum Teil erfolgreich. Während in Norwegen und Finnland die Gewerkschaftsbewegungen mit Erfolg eine Verstärkung der staatlich subventionierten Kurzarbeit verlangten, scheiterte die schwedische Gewerkschaftsbewegung mit ihren Forderungen nach einer stärkeren Unterstützung für die einheimische Automobilindustrie (Jochem 2010, 2011b).

Die Bürgerinnen und Bürger des Nordens nutzten klassische Partizipationskanäle der repräsentativen und pluralistischen Demokratie. Nur in Island verstärkten sich zivilgesellschaftliche bzw. direktdemokratische Partizipationsformen. In den anderen Ländern waren hauptsächlich Wahlen ein Forum des bürgerlichen Plebiszits in der Krise. Und diese Plebiszite honorierten unterschiedliche Wege des Krisenmanagements in Norwegen und Schweden ebenso wie sie zur Abwahl von als nicht leistungsfähig eingestuften Krisenmanagern in Dänemark und Finnland führten. 


\subsection{Entscheidungsfindung}

Krisen sind die Stunden der Exekutive. Unter Zeitdruck Unsicherheiten abwägen, politisch riskante Entscheidungen fällen und diese in adminstratives Handeln überführen, dies sind die Maximen in politisch ,unsicheren ' Zeiten. Auch für die Finanzkrise treffen diese politikwissenschaftlichen Binsenweisheiten zu. Die formalen Institutionen der nordischen Wettbewerbsdemokratien ohne zahlreiche Vetopunkte, aber mit in höchstem Maße effizienten Staatsverwaltungen, bieten optimale institutionelle Rahmenbedingungen für rasches politisches Handeln.

Der Entscheidungsmodus der nordischen Krisenpolitik wurde vor allem von Verhandlungen zwischen Koalitionsparteien geprägt. Im dänischen Minderheitsparlamentarismus waren es intensive Verhandlungen mit der rechtspopulistischen Dänischen Volkspartei, die zentrale Aspekte des Krisenmanagements bestimmten. In den anderen Ländern mit parlamentarischen Mehrheiten erfolgten die Verhandlungen auf der Spitzenebene zwischen den Koalitionspartnern. Gleichzeitig - und nicht verwunderlich - dominierten die Ministerien mit ihrem Sachverstand (und ihren Interessen) die wichtigsten Entscheidungen (Jochem 2012: 161-167).

Eine breite Einbeziehung von Verbänden in die politische Entscheidungsfindung und -implementation fand hingegen im Norden kaum statt. Die nordischen Varianten des Korporatismus führten in der Vergangenheit zu politischen Konzertierungen mit den wichtigsten Verbänden von Arbeit und Kapital. Während in der unmittelbaren Krisenphase eine solche Konzertierung aufgrund des Zeitdrucks nicht angebracht erschien, so ist zu konstatieren, dass auch nach den unmittelbaren Krisenjahren keine Konzertierungspraktiken im Norden zu beobachten sind (mit der partiellen Ausnahme Norwegens). In Schweden sind die Anläufe für eine Revitalisierung des grundlegenden Arbeitsmarktabkommens aus den 1930er-Jahren (,saltsjöbadsavtalet') bis auf den heutigen Tag blockiert. Die Lohnverhandlungen führten zwar in der unmittelbaren Krise zu moderaten Abschlüssen und durchaus flexiblen Verhandlungslösungen auf betrieblicher oder sektoraler Ebene (Svalund et al. 2013). Allerdings verblieben diese Kooperationen sehr oft auf betrieblicher Ebene, eine gesamtwirtschaftliche Konzertierung konnte im Norden (mit der teilweisen Ausnahme von Norwegen) nicht mehr erreicht werden.

Die Schwächung dieser informellen Formen der Entscheidungsfindung wird in Schweden durch eine gezielte Regierungspolitik zur Schwächung der Gewerkschaften verstärkt. Während die Machtbasis der Gewerkschaften überall im Norden rückläufig ist, bricht sie in Schweden nahezu ein (Jochem 2012: 117; Kjellberg 2013). Die bürgerliche Koalition hat seit 2006 die finanziellen Rahmenbedingungen der Arbeitslosenversicherungen verschlechtert. Als Konsequenz verlassen immer mehr Arbeitnehmer die freiwilligen Arbeitslosenversicherungen und dies führt nicht nur zu Problemen bei der finanziellen Absicherung von Arbeitslosen, sondern auch - da diese Versicherungskassen von den Gewerkschaften verwaltet werden - zu stark rückläufigen Mitgliederzahlen der Gewerkschaften. In den anderen nordischen Ländern schwächt sich zwar 
die Machtbasis der Gewerkschaftsbewegungen ebenfalls, allerdings ist nur in Schweden ein solchermaßen expliziter Rückgang zu verzeichnen.

Im Norden dominieren in der Krise immer stärker Expertengremien die demokratische Entscheidungsfindung. Es setzt sich auch im Norden ein Trend durch, rein akademisch besetzte Expertengremien ohne Verankerung an gesellschaftliche Verbände die demokratische Beschlussfassung vorbereiten $\mathrm{zu}$ lassen. Ein prominentes Beispiel ist der Finanzpolitische Rat (,finanspolitiksa rådet') in Schweden. Okonomen evaluieren die Bandbreite der fiskalischen und ökonomischen Politik der Regierungen und intervenieren beständig in den Medien (und nicht nur zu einem bestimmten Termin im Jahr, wie zum Beispiel der Sachverständigenrat zur Begutachtung der gesamtwirtschaftlichen Entwicklung in Deutschland). Der Einfluss dieses Gremiums auf die faktische Krisenpolitik der schwedischen Regierung ist schwer abzuschätzen. Zumindest in wichtigen Punkten nahmen die Experten eine kritische Position gegenüber den Regierungsmaßnahmen ein. Vor dem Hintergrund abgeschwächter korporatistischer Beratungsgremien öffnen sich solchen akademisch dominierten Expertenzirkeln immer stärker Einflusskanäle auf die öffentliche Meinung.

Die nordischen Länder sind aber auch eingebettet in internationale Prozeduren der Entscheidungsfindung, insbesondere auf europäischer Ebene. Während für die meisten nordischen Länder diese Verflechtung keine unmittelbar gravierenden Einschränkungen der nationalen Handlungsfreiheit bewirkte, war dies im isländischen Fall anders. ${ }^{14}$ Mit Beginn der Finanzkrise und den enormen fiskalischen Belastungen für den Staathaushalt war Island auf ausländisches Kapital angewiesen. Im Herbst 2008 konnte sich die isländische Regierung mit dem IWF auf ein Hilfspaket einigen, gleichzeitig unterstützten die nordischen Nachbarländer (aber auch Russland) die Inselrepublik. Diese finanzielle Abhängigkeit wirkte sich auf die politische Entscheidungsfindung aus. Die beeindruckenden Konsolidierungsbemühungen des Landes seit 2008 sind nicht zuletzt auch auf Forderungen des IWF zurückzuführen. Und der Konflikt über die Icesave-Abkommen zeigt, welchen Spagat die isländische Regierung zwischen einerseits demokratischen Interessen der Bürger und internationalen Verpflichtungen andererseits auszuhalten hatte.

Ebenso wirken sich formale Regeln der Europäischen Zentralbank auf die territorialstaatlichen Entscheidungsprozesse im Norden aus. Island, Schweden und Norwegen konnten durch ihre währungspolitischen Freiheiten die nationalen Währungen auf den Märkten floaten lassen (Dølvik/Goul Andersen/Vartiainen 2011). Die sich daraus ergebenden faktischen Abwertungen beflügelten unmittelbar und - vor allem in Island - in nicht unerheblichem Ausmaße die Wettbewerbsfähigkeit der nationalen

14 Hier liegt die Betonung auf unmittelbare Konsequenzen für die nordischen Regierungen. In einem längeren Zeithorizont wirken die Vorgaben europäischer Gremien und Akteure auch auf die anderen nordischen Regierungen ein. Das Primat der Haushaltskonsolidierung zum Beispiel kann auch von den nordischen Ländern nicht ignoriert werden, die nicht unmittelbar Mitglied der EU bzw. des Euroraums sind. 
Exportindustrien. Anders ist die Ausgangslage in Finnland und Dänemark. Die dortige Dominanz des Euro versperrt einen solchen Reformweg, über eine externe Abwertung die nationale Wettbewerbsfähigkeit zu beflügeln. In diesen Ländern wird in der Finanzkrise zwangsläufig auf ,interne Anpassungen', also Lohnanpassungen sowie Strukturreformen der Arbeitsmärkte gesetzt.

Eine augenscheinliche Abhängigkeit der nordischen Länder in ihrer Entscheidungsfähigkeit wurde in der Vergangenheit vor allem im Hinblick auf den Europäischen Gerichtshof (EuGH) deutlich. In einer Reihe von Verfahren hat der EuGH die Freizügigkeitsprinzipien über nationales Recht und nationale Institutionen gesetzt. Vor allem durch das Laval- und Viking-Verfahren wurden die schwedischen und finnischen Sozialpartner in ihrer Regulierungskompetenz von höchstrichterlicher Seite eingeschränkt (Blanke 2008; Höppner 2008; Dølvik/Visser 2009). Just diese Einschränkung nationaler Entscheidungskompetenz untergräbt in hohem Maße die Möglichkeit der Selbstregulierung von in hohem Maße organisierten Akteuren auf den nordischen Arbeitsmärkten.

Demokratische Entscheidungsprozeduren konzentrierten sich in der Finanzkrise auf die Regierung und die Exekutive. Auch im weiteren Verlauf der Krise kam es kaum zu Konzertierungsversuchen oder einer weiteren Öffnung der Entscheidungsfindung auf gesellschaftliche Akteure. Insbesondere im isländischen Fall wird deutlich, wie stark die Entscheidungsfindung durch Verhandlungen mit internationalen Akteuren und dem IWF geprägt wurde. Aber auch für die anderen nordischen Mitglieder der Europäischen Union zeigen die Fälle Laval und Viking, wie sich europäisches Recht auf die nordische Entscheidungsfreiheit auswirkt und hierbei die Selbststeuerung gesellschaftlicher Akteure, also informelle Institutionen demokratischer Herrschaft, ausgehöhlt werden.

\subsection{Implementierung}

Die nordischen Demokratien verfügen über effiziente Implementationsroutinen politischer Entscheidungen. In keinem der nordischen Länder - mit der Ausnahme Islands - konnten politische Entscheidungen während der Krise nicht effizient umgesetzt werden. Diese Effizienz des Implementationsprozesses bezieht sich nicht nur auf die Ausgabenseite der öffentlichen Haushalte. Auch die Besteuerungseffizienz ist im Norden immer noch sehr hoch. ${ }^{15}$ So besteht im Norden zwar ein nicht unerheblicher Steuerdruck auf die Bevölkerungen, und die starken rechtspopulistischen Parteien

15 Die nordischen Länder haben jüngsten Schätzungen zufolge durchaus mit einer gewissen Schattenwirtschaft zu kämpfen (Schneider/Buehn 2012). Zum einen ist jedoch der Anteil des am Staat vorbei erwirtschafteten Wohlstands immer noch niedriger als in vielen Ländern Kontinental- und vor allem Südeuropas. Zum anderen führen einfache Steuersysteme mit wenigen Ausnahmeregelungen im Norden nicht zu gravierenden Steuerausfällen für die öffentlichen Haushalte. 
des Nordens fordern zudem weitergehende Steuersenkungen ein. Allerdings wird die Steuersenkungspolitik im Norden durchaus mit Bedacht gewählt, wenngleich auch hier die Länderunterschiede beachtlich sind. So ist die bürgerliche Regierungspolitik in Dänemark zögerlicher gewesen, Steuerreduzierungen durchzuführen, als dies am jüngsten Beispiel bürgerlicher Steuersenkungspolitik in Schweden zu beobachten ist. Gleichwohl kann festgestellt werden, dass in Dänemark, Finnland und Schweden ebenso wie in Norwegen die Haushaltspolitik äußerst solide ist - so sind die nordischen Länder und Luxemburg die einzigen Mitgliedsländer der EU, die auch in der Krise die Konvergenzkriterien von Maastricht weiter eingehalten hatten (Dølvik/Goul Andersen/Vartiainen 2012: 15f.).

Mitunter wurden zentrale Akteure der Politikimplementation aber auch in der Krise explizit gestärkt. Mit dem ökonomischen Abschwung gerieten insbesondere die regionalen und lokalen Gebietskörperschaften in fiskalische Bedrängnis. Auf Drängen der betroffenen Akteure und der Gewerkschaften des öffentlichen Sektors erhöhte zum Beispiel die schwedische Regierung die zentralstaatlichen Zuwendungen an diese Gebietskörperschaften. Damit sollte die Funktionsweise der sozialen Sicherungssysteme, also vor allem die auf lokaler und regionaler Ebene angesiedelte Implementation der noch weitgehend öffentlichen sozialen Humandienstleistungen, in der Krise abgesichert werden (Jochem 2010).

\subsection{Rechtssicherheit}

Der Grad der Rechtsstaatlichkeit ist im Norden - mit Abstrichen für Island - sehr umfassend ausgeprägt. In den großen nordischen Territorialstaaten sind juristische Wege für die Bevölkerung gegeben, ihren Widerstand gegen politische Entscheide auszudrücken. Dieser Weg wird im Norden noch ergänzt durch eine Vielzahl von Ombudsmännern (und Ombudsfrauen), die als Anwälte der Bürgerinteressen in unterschiedlichen Belangen agieren.

Das isländische Rechtssystem wird hingegen von nepotistischen Tendenzen geprägt. Durch die politische Hegemonie der Unabhängigkeitspartei und (in eingeschränktem Maße) der Fortschrittspartei konnten diese Parteien die Besetzung der höchsten Richter für sich monopolisieren. Auch Ämter im Obersten Gerichtshof wurden teilweise Verhandlungsmasse im engen Beziehungsgeflecht zwischen Politik, Wirtschaft und Finanzsystem. Zum Teil versuchten bürgerliche Regierungen, Entscheide des Obersten Gerichtshofs zu ignorieren. Während zum Beispiel 1998 der Oberste Gerichtshof die bestehenden Regulierungen der Fischfangquoten als nicht verfassungskonform zurückwies, reagierte die Politik nicht mit einer Reform der Fischereipolitik, sondern übte Druck auf den Obersten Gerichtshof aus. Dieser revidierte schließlich im Jahr 2000 seinen Entschluss, allerdings intervenierte im Jahr 2007 das UN-Menschenrechtskommitee und bekräftigte explizit das ursprüngliche Urteil des Obersten Gerichtshofs (Gylfason 2012). Im Verlauf der direktdemokratisch forcierten 
Verfassungsreform intervenierte schließlich der Oberste Gerichtshof Islands, indem er eine Wahl zur verfassungsgebenden Versammlung 2010 für ungültig erklärte. Die rotgrüne Regierung umging dieses Urteil und lud alle 25 gewählten Vertreter in ein anderes Gremium ein, das konkrete Vorgaben für eine Verfassungsreform erarbeiten sollte. Diese Beispiele zeigen, wie brüchig die Rechtssicherheit in Island in der vergangenen Dekade war (Jochem 2013c).

\section{Fazit}

Die politischen Systeme des europäischen Nordens sind bunter und vielschichtiger als gemeinhin angenommen (Alestalo/Hort/Kuhnle 2009; Bengtsson et al. 2013; Bergmann/Strøm 2011; Jochem 2012). Jenseits innerskandinavischer Unterschiede ist für alle fünf nordischen Territorialstaaten hervorzuheben, dass ihnen in den meisten Studien der empirischen Demokratieforschung eine hohe Demokratiequalität zugesprochen wird. Just diese demokratische Qualität, die demokratische Transparenz und Nachvollziehbarkeit des politischen Prozesses, der politische Pragmatismus sowie die breite Integration unterschiedlichster Interessen in den politischen Entscheidungsprozess sind allerdings keine kulturell determinierten Konstanten nordischer Politik. Diese Qualität der nordischen Demokratien ist kontingent in dem Sinne, dass in der jüngsten Vergangenheit sowohl im Bereich der formalen, vor allem aber im Bereich der informellen Institutionen Veränderungen stattfanden. In der Mehrzahl der beobachtbaren Fälle stärken diese weniger die konsensuale Seite des demokratischen Prozesses, sondern eher Aspekte des Wettbewerbs, der Konkurrenz sowie abnehmender Verhandlungsnotwendigen mit den hiermit einhergehenden Anreizen zur Kompromissbildung.

Die formalen Institutionen entwickelten sich in den vergangenen Jahren im europäischen Norden in Richtung einer Stärkung parlamentarischer Prinzipien sowie einer Stärkung der Exekutive. Dies wird augenscheinlich in der Verfassungsreform in Finnland, der angestrebten (aber gescheiterten) Verfassungsrevision in Island sowie der jeweiligen Stärkung des parlamentarischen Wettbewerbs in Schweden und Dänemark.

Die informellen Institutionen wirkten lange Zeit als funktionales Korrektiv gegen das institutionell angelegte Wettbewerbsprinzip im Norden. Sei es die breite Integration verbandlicher Interessen in korporatistischen Institutionen, sei es die - mitunter aus parlamentarischer Not geborene - Bereitschaft zu blockübergreifenden Koalitionen mit dem einhergehenden Pragmatismus der politischen Akteure, stets wirkten solche informellen Institutionen mäßigend auf den durch die formalen Institutionen vorgegebenen Prozess des Wettbewerbs und der elektoralen Konkurrenz. Keineswegs kann für die fünf nordischen Territorialstaaten jedoch ein Gleichklang bei der Erosion dieser informellen Institutionen konstatiert werden. Insbesondere das für die skandinavischen Demokratien beispielhafte schwedische Modell offenbart jedoch eine rapi- 
de voranschreitende Ausdünnung informeller Institutionen der Kompromissbildung sowie der integrativen demokratischen Politik.

Letztlich bleibt die Frage nach den Gründen und Konsequenzen dieser institutionellen Entwicklungen in den fünf nordischen Demokratien. Erstens kann argumentiert werden, dass der Siegeszug des individualistisch-rationalen Wettbewerbsgedankens auch an den Grenzen des ehemals sozialdemokratisch-solidarisch geprägten Nordens nicht halt gemacht hat. Veränderte Wertvorstellungen und Erwartungen an legitimes politisches Handeln verändern dort nicht nur informelle Institutionen, sondern wirken sich im Laufe der Zeit auch auf die formalen Institutionen aus. Nicht nur im Norden erodiert zum Beispiel die Machtbasis der Arbeiterbewegung. Allerdings ist diese Erosion für die sozialdemokratisch dominierten Demokratien in Skandinavien von besonderer Relevanz. Zweitens impliziert die europäische Integration mit ihren Freizügigkeitsimperativen sowie einer daraus resultierenden negativen Integration auch die Erosion politischer Regeln, die im Norden dynamische Märkte und Gesellschaften lange Zeit gezügelt hatten. Die arbeits- und tarifrechtlichen Konflikte in den Fällen Viking und Laval zeigen besonders offensichtlich (Blanke 2008, Höppner 2008, Dølvik/Visser 2009), wie sich nationalstaatliche Regeln am EU-Recht reiben - und der EuGH mit Macht europäisches Recht auch gegen nationale Rechtstraditionen und informelle Institutionen durchsetzt.

„The Nordic Model never existed - but does it have a future?" Auf diesen Nenner brachte Lars Mjøset bereits vor mehr als zehn Jahren (Mjøset 2001) einerseits die demokratische Vielfalt im Norden, andererseits beantwortete er die Frage nach der Zukunft des nordischen Modells durchaus hoffnungsvoll. Nimmt man diese Frage zur Zukunft der eigentümlichen nordischen Demokratien zwischen Wettbewerbsimperativen und Kompromissnotwendigkeiten wieder auf, dann erscheinen heute die $\mathrm{Zu}$ kunftsaussichten des nordischen demokratischen Modells deutlich unsicherer als dies Lars Mjøset vor über zehn Jahren prognostizierte. Die international zunehmende Bewunderung der nordischen Demokratien auch und gerade in der globalen Finanzkrise (Economist 2013) fällt zeitlich zusammen mit einer augenscheinlichen Erosion bedeutsamer Institutionen in den nordischen Demokratien. Die Modelle werden also hinsichtlich ihrer Leistungskraft gegenwärtig hoch geschätzt; nur selten wird allerdings dabei wahrgenommen, dass unter der Oberfläche vorzüglicher Leistungsbilanzen sich die institutionellen Fundamente deutlich verändern.

\section{Bibliographie}

Alestalo, Matti/Hort, Sven E.0./Kuhnle, Stein, 2009: The Nordic Model: Conditions, Origins, Outcomes, Lessons, Hertie School of Governance Working Papers No. 41, June 2009, Berlin: Hertie School of Governance.

Arter, David, 1987: Politics and Policy-Making in Finland, Sussex: Wheatsheaf Books/New York: St. Martin's Press. 
Arter, David, 2006: Democracy in Scandinavia, Manchester: Manchester UP.

Arter, David, 2008: Scandinavian Politics, Second Edition, Manchester: Manchester UP.

Arter, David, 2013: The "Hows", not the "Whys" or the „Wherefores": The Role of Intra-party Competition in the 2011 Breakthrough of the True Finns, in: Scandinavian Political Studies 36, No. 2, S. 99-120.

Aylott, Nicholas, 2011: Parties and Party Systems in the North, in: Bergmann, Torbjörn/ Strøm, Kaare (Hrsg.): The Madisonian Turn. Political Parties and Parliamentary Democracy in Nordic Europe, Michigan, S. 297-328.

Bengtsson, Asa/Hansen, Kasper M./Hardarson, Olafur P./Narud, Hanne Marthe/ Oscarsson, Henrik, 2013: The Nordic Voter. Myths of Exceptionalism, Essex: ECPR Press.

Bergmann, Torbjörn/Strøm, Kaare (Hrsg.), 2011: The Madisonian Turn. Political Parties and Parliamentary Democracy in Nordic Europe, Michigan, Michigan UP.

Blanke, Thomas, 2008: Die Entscheidungen des EuGH in den Fällen Viking, Laval und Rueffert Domestizierung des Streikrechts und europaweite Nivellierung der industriellen Beziehungen, Oldenburger Studien zur Europäisierung und zur transnationalen Regulierung Nr. 18/2008, Universităt Oldenburg.

Dølvik, Jon Erik/Visser, Jelle, 2009: Free Movement, Equal Treatment and Worker Rights: Can the EU solve its Trilemma of Fundamental Principles?, in: Industrial Relations fournal 49 (6), S. 315350.

Dølvik, Jon Erik/Goul Andersen, Jørgen/Vartiainen, Juhana, 2011: The Nordic Social Models: Crisis, Consolidation and Transformation, Paper for the Council for European Studies, Symposium "The European Social Models Facing Global Economic Crisis“, 20-22 June 2011, Amsterdam.

Dølvik, Jon Erik/Goul Andersen, Jørgen/Vartiainen, Juhana, 2012: Nordic Models in Turbulent Times. Developments in Social and Labour Market Governance since the Crisis in the 1990s, Background Paper RC 19 Conference „Welfare States Facing Global Turbulence, Ageing and Migration: Rising to the Occasion, Coping or Adjusting Downwards?", S. 23-24 August 2012, Oslo.

Economist 2013, Special Report: The Nordic Countries, Northern Lights (online: http://www.economist.com/news/special-report/21570840-nordic-countries-are-reinventingtheir-model-capitalism-says-adrian) (zuletzt aufgerufen 14.10.2013)

Esaiasson, Peter/Heidar, Knut (Hrsg.), 2000: Beyond Westminster and Congress: The Nordic Experience, Ohio State University Press.

Esping-Andersen, Gøsta, 1985: Politics Against Markets: The Social Democratic Road to Power, Princeton: Princeton UP.

Eythórsson, Grêtar Thór/Jahn, Detlef, 2009: Das politische System Islands, in: Ismayr, Wolfgang (Hrsg.), 2009: Die politischen Systeme Westeuropas, 4. aktualisierte und erweiterte Aufl., Wiesbaden: VS Verlag, S. 195-218.

Fridberg, Torben/Kangas, Olli, 2008: Social Capital, in: Ervasti, Heikki/Fridberg, Torben, Hjerm, Mikael/Ringdal, Kristen (eds.), 2008: Nordic Social Attitudes in a European Perspective, Cheltenham: Edward Elgar, S. 65-85.

Goul Andersen, Jørgen, 2013: Danmarks selvskabte økonomiske krise - et økonomisk og politisk paradoks, (online: http://videnskab.dk/politologisk-arbog-2013/danmarks-selvskabteokonomiske-krise-et-okonomisk-og-politisk-paradoks) (zuletzt aufgerufen 14.10.2013).

Growiec, Katarzyna/Vilhelmsdóttir, Sjöfn/Cairns, David, 2012: Social Capital and the Financial Crisis: The Case of Iceland, CIES e-Working Papers No. 138/2012, Lisboa: CIES.

Gylfason, Thorvaldur, 2012: From Collapse to Constitution: The Case of Iceland, CESifo Working Paper No. 3770, Munich: CESifo.

Heidar, Knut (Hrsg.), 2004: Nordic Politics. Comparative Perspectives, Oslo: Universitetsforlaget. Henningsen, Bernd, 2013: Gemeinschaft versus Staat, Nation versus Europa. Nordeuropäische Gemeinschaftskonstruktionen und die modernen Traditionsbruche, in: Lehnert, Detlef (Hrsg.): 
Gemeinschaftsdenken in Europa. Das Gesellschaftskonzept „Volksheim“ im Vergleich, 19001938, Köln u. a.: Böhlau Verlag, S. 39-72.

Henningsen, Bernd/Jochem, Sven (Hrsg.), 2014: Sonderheft Skandinavien, Der Bürger im Staat, Stuttgart: Landeszentrale fur politische Bildung (i. E.).

Hilson, Mary, 2008: The Nordic Model. Scandinavia since 1945, London: Reaktion Books.

Höppner, Martin, 2008: Social Europe? The European Project after Vlking and Laval, in: Die Mitbestimmung (English Online Issue).

Holmberg, Sören/Rothstein, Bo (Hrsg.), 2012: Good Government.The Relevance of Political Science, Cheltenhamn: Edward Elgar.

Jahn, Detlef, 2009: Das politische System Schwedens, in: Ismayr, Wolfgang (Hrsg.), 2009: Die politischen Systeme Westeuropas, 4. aktualisierte und erweiterte Aufl., Wiesbaden: VS Verlag. 107-149.

Jochem, Sven, 2010: Comparative Crisis Management. Country Report on Sweden, Bertelsmann Stiftung, Gutersloh: Bertelsmann Stiftung.

Jochem, Sven, 2011a: Die schwedische Reichstagswahl vom 19. September 2010 - Zur Logik einer sich auflösenden sozialdemokratischen Hochburg, in: Zeitschrift fur Parlamentsfragen 1/2011, S. 98-111.

Jochem, Sven, 2011b: Nordic Employment Policies - Change and Continuity Before and During the Financial Crisis, in: Social Policy \& Administration 45, 2, S. 131-145.

Jochem, Sven, 2012: Die politischen Systeme Skandinaviens, Wiesbaden: VS Verlag.

lochem, Sven, 2013a: Abkehr vom Minderheitenparlamentarismus? Die skandinavischen Koalitionsdemokratien, in: Decker, Frank/lesse, Eckhard (Hrsg.): Die deutsche Koalitionsdemokratie vor der Bundestagswahl 2013, Baden-Baden: Nomos, S. 597-618.

Jochem, Sven, 2013b: Religion und Wohlfahrtsstaat in Schweden - Der Einfluss lutherischen Glaubens jenseits der Staatskirche, in: Gabriel, Karl/Reuter, Hans-Richard (Hrsg.): Religion und Wohlfahrtsstaatlichkeit in Europa, Tubingen: Mohr (i. E.).

Jochem, Sven, 2013c: Habermas on Ice - Deliberative Verfassungsexperimente, demokratischer Nepotismus und Parteienwettbewerb in Island, unveröffentlichtes Manuskript.

Kjellberg, Anders, 2013: Växande avgiftsskillnader i a-kassan - ökad social polarisering, Studies in Social Policy, Industrial Relations, Working Life and Mobility, Research Reports 2010:2 (Aktualisierung 10.09.2013).

Lijphart, Arend, 1999: Patterns of Democracy. Government Forms and Performance in Thirty-Six Countries, New Haven and London: Yale University Press.

Mjøset, Lars 2001: The Nordic Model Never Existed, but Does it Have a Future?, in: Jessop, Bob (Hrsg.): Regulation Theory and The Crisis of Capitalism, Vol. 2: European and American Perspectives on Regulation, Cheltenham, Edward Elgar, S. 283-303.

Mjøset, Lars (Hrsg.), 2011: The Nordic Varieties of Capitalism, Bingley: Emerald.

Oberg, PerOla/Svensson, Torsten/Christiansen, Peter Munk/Nørgaard, Asbjørn Sonne/ Rommetvedt Hilmar/Thesen, Gunnar, 2011: Disrupted Exchange and Declining Corporatism: Government Authority and Interest Group Capability in Scandinavia, in: Government and Opposition 46, No. 3, S. 365-391.

Rothstein, Bo, 2010: Happiness and the Welfare State, in: Social Research 77, S. 1-28.

Rydgren, Jens, 2009: Social Isolation? Social Capital and Radical Right-wing Voting in Western Europe, in: Journal of Civil Society, 5, 2, S. 129-150.

Rydgren, Jens, 2010: Radical Right-wing Populism in Denmark and Sweden: Explaining Party System Change and Stability, in: SAIS Review, 30, 1, S. 57-71.

Rydgren, Jens, 2011: A legacy of ,uncivicness'? Social capital and radical right-wing populist voting in Eastern Europe, in: Acta Politica 46, S. 132-157.

Schmidt, Manfred G. 2006: Demokratietheorien, Wiesbaden: VS. 
Schneider, Friedrich/Buehn, Andreas, 2012: Shadow Economies in Highly Developed OECD Countries: What are the Driving Forces?, IZA DP No. 6891, Bonn: IZA.

Siaroff, Alan, 1999a: Corporatism in 24 industrial democracies: Meaning and Measurement, in: European Journal of Political Research 36, S. 175-205.

Rokkan, Stein, 1999: State Formation, Nation Building and Mass Politics: The Theory of Stein Rokkan, Oxford: Oxford UP.

Strøm, Kaare, 1990: Minority Government and Majority Rule, Cambridge: Cambridge University Press.

Svalund, Jørgen/Bergström Casinowsky, Gunilla/Dølvik, Jon Erik/Håkansson, Kristina/Jarvensivu, Anu/Kervinen, Heidi/Møberg, Rasmus Juul/Piirainen, Tatu, 2013: Stress testing the Nordic models: Manufacturing labour adjustments during crisis, in: European Journal of Industrial Relations (online first).

Uslaner, Eric M./Rothstein, Bo, 2012: Mass Education, State-Building and Equality. Searching for the Roots of Corruption, The Quality of Government Institute, Working Paper Series 2012: 5 , Göteborg, QoG. 